Supporting Information for:

\title{
Bisdithiazolyl Quinones: Stabilizing Organic Electrode Materials with Sulfur-Rich Thiazyl Motifs
}

Madison R. Tuttle and Shiyu Zhang*

Department of Chemistry and Biochemistry, The Ohio State University, 100 West 18th Avenue, Columbus, Ohio 43210, United States

\section{Contents}

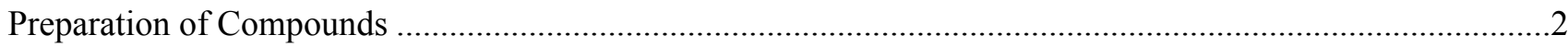

Synthesis and characterization of benzo[1,2-d:4,5-d']bis([1,2,3]thiadiazole)-4,8-dione (NNS) ................4

Synthesis and characterization of benzo[1,2-c:4,5-c']bis([1,2,5]thiadiazole)-4,8-dione (NSN)..................5

Synthesis and Characterization of benzo[1,2-d:5,4-d']bis([1,2,3]dithiazole)-2-ium-8-olate (NSS).............8

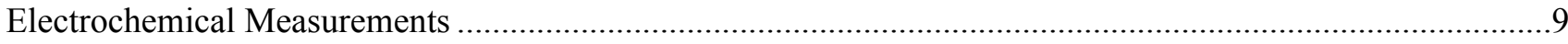

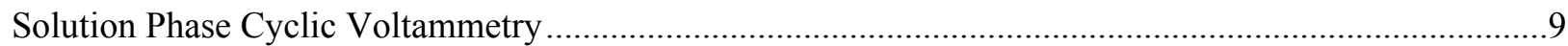

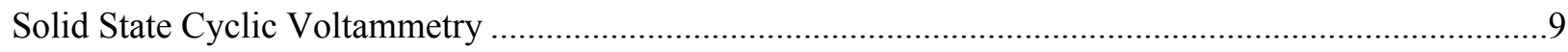

Potentio-electrochemical Impedance Spectroscopy (PEIS) ......................................................................10

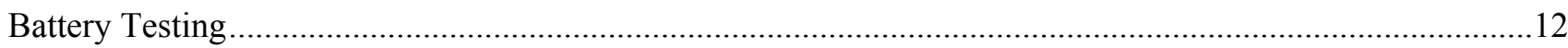

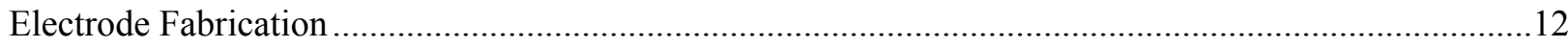

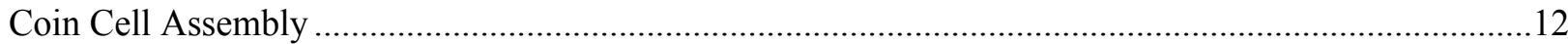

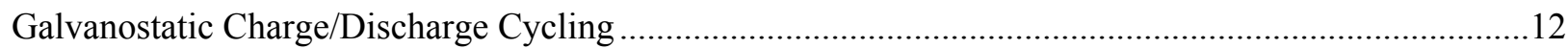

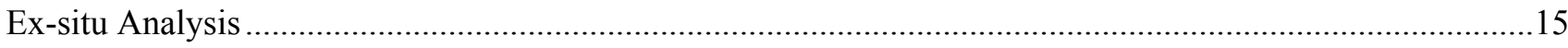

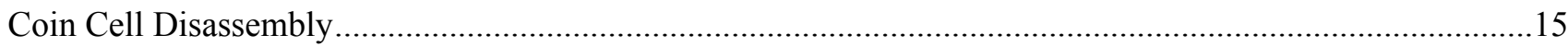

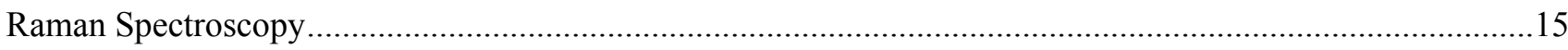

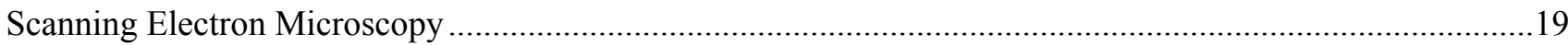

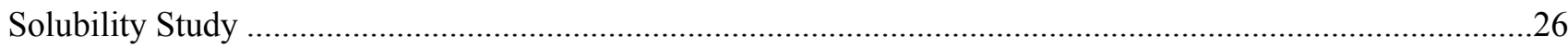

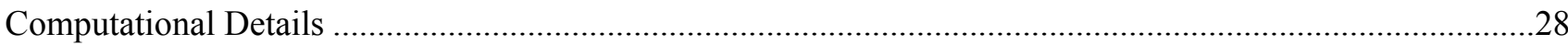


Scheme S1. Synthesis of NNS.<smiles></smiles>

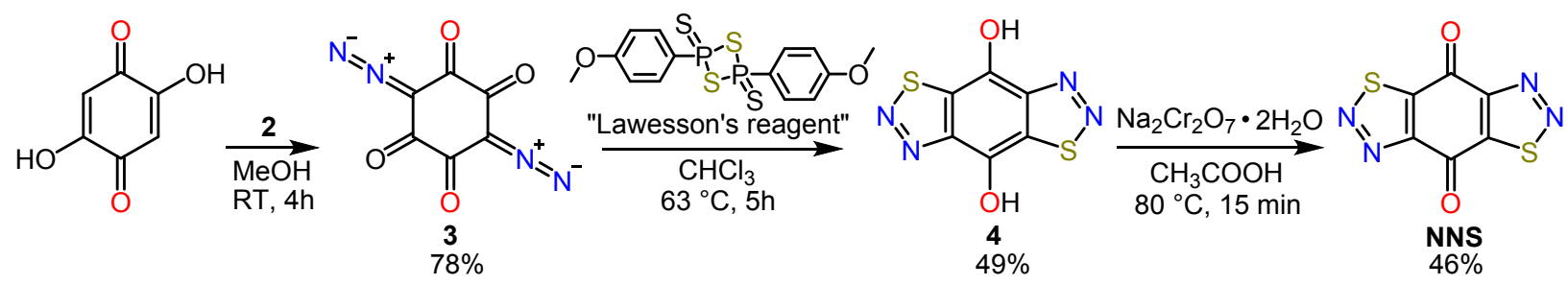

\section{Synthesis and characterization of 2-chloro-3-ethylbenzo[d]thiazol-3-ium tetrafluoroborate (1)}

2-chloro-3-ethylbenzo[d]thiazol-3-ium tetrafluoroborate was prepared according to a modified literature procedure. ${ }^{1}$ A round-bottom flask was charged with a solution of triethyloxonium tetrafluoroborate (Meerwein's reagent, $11.19 \mathrm{~g}, 58.88 \mathrm{mmol}$, Alfa Aesar) in DCM (30 mL). The flask was sealed with a septum cap and placed under a positive pressure of $\mathrm{N}_{2}$. At room temperature, 2-chlorobenzothiazole (9.08 g, $53.53 \mathrm{mmol}$, TCI America) was added. The solution was refluxed at $45^{\circ} \mathrm{C}$ with stirring for 1 hour to afford a white precipitate. The mixture was then chilled in the freezer overnight, and the white precipitate was collected by vacuum filtration to yield the pure product $(12.06 \mathrm{~g}, 79 \%) .{ }^{1} \mathrm{H}$ NMR (DMSO- $\left.d_{6}, 400 \mathrm{MHz}\right): \delta 7.65(\mathrm{~m}, 1 \mathrm{H}), \delta 7.37(\mathrm{~m}, 2 \mathrm{H}), \delta 7.20(\mathrm{~m}$, $1 \mathrm{H}), \delta 3.98(\mathrm{q}, 2 \mathrm{H}), \delta 1.21(\mathrm{t}, 3 \mathrm{H})$. The ${ }^{1} \mathrm{H}$ NMR spectrum of the product matches that reported in the literature. ${ }^{1}$

\section{Synthesis and characterization of 2-azido-3-ethylbenzo[d]thiazol-3-ium tetrafluoroborate (2)}

2-azido-3-ethylbenzo[d]thiazol-3-ium tetrafluoroborate was prepared according to a modified literature procedure. $^{2}$ A round-bottom flask charged with a solution of 2-chloro-3-ethylbenzo[d]thiazol-3-ium tetrafluoroborate $(\mathbf{1}, 7.19 \mathrm{~g}, 25.18 \mathrm{mmol})$ in $\mathrm{MeOH}(50 \mathrm{~mL})$ was cooled to $0{ }^{\circ} \mathrm{C}$ and sodium azide $(1.64 \mathrm{~g}, 25.18$ mmol) was added in one portion. The reaction mixture slowly turned lilac (light purple) and was stirred vigorously at $\sim 10-15^{\circ} \mathrm{C}$ for 10 minutes. The reaction mixture was then cooled to $-20^{\circ} \mathrm{C}$ and stirred for $20 \mathrm{~min}$. The resulting white precipitate was filtered and washed with a small amount of cold $\mathrm{MeOH}$. The volume of the purple filtrate was reduced to half and cooled in the freezer to afford more white precipitate. The precipitate was again filtered and washed. The process was repeated once more with the remaining purple filtrate and all three batches of white precipitate were combined (4.83 g, 66\%). The crude product was recrystallized in $\mathrm{MeOH}$ $(50 \mathrm{~mL})$ to yield white, needle-like crystals as the pure product (1.85 g, 25\%). ${ }^{1} \mathrm{H}$ NMR (DMSO- $d_{6}, 400 \mathrm{MHz}$ ): $\delta 8.38(\mathrm{~d}, 2 \mathrm{H}), \delta 8.21(\mathrm{~d}, 1 \mathrm{H}), \delta 7.86(\mathrm{t}, 1 \mathrm{H}), \delta 7.76(\mathrm{t}, 1 \mathrm{H}), \delta 4.53(\mathrm{q}, 2 \mathrm{H}), \delta 1.42(\mathrm{t}, 3 \mathrm{H})$ (Figure $\mathrm{S} 1)$. 


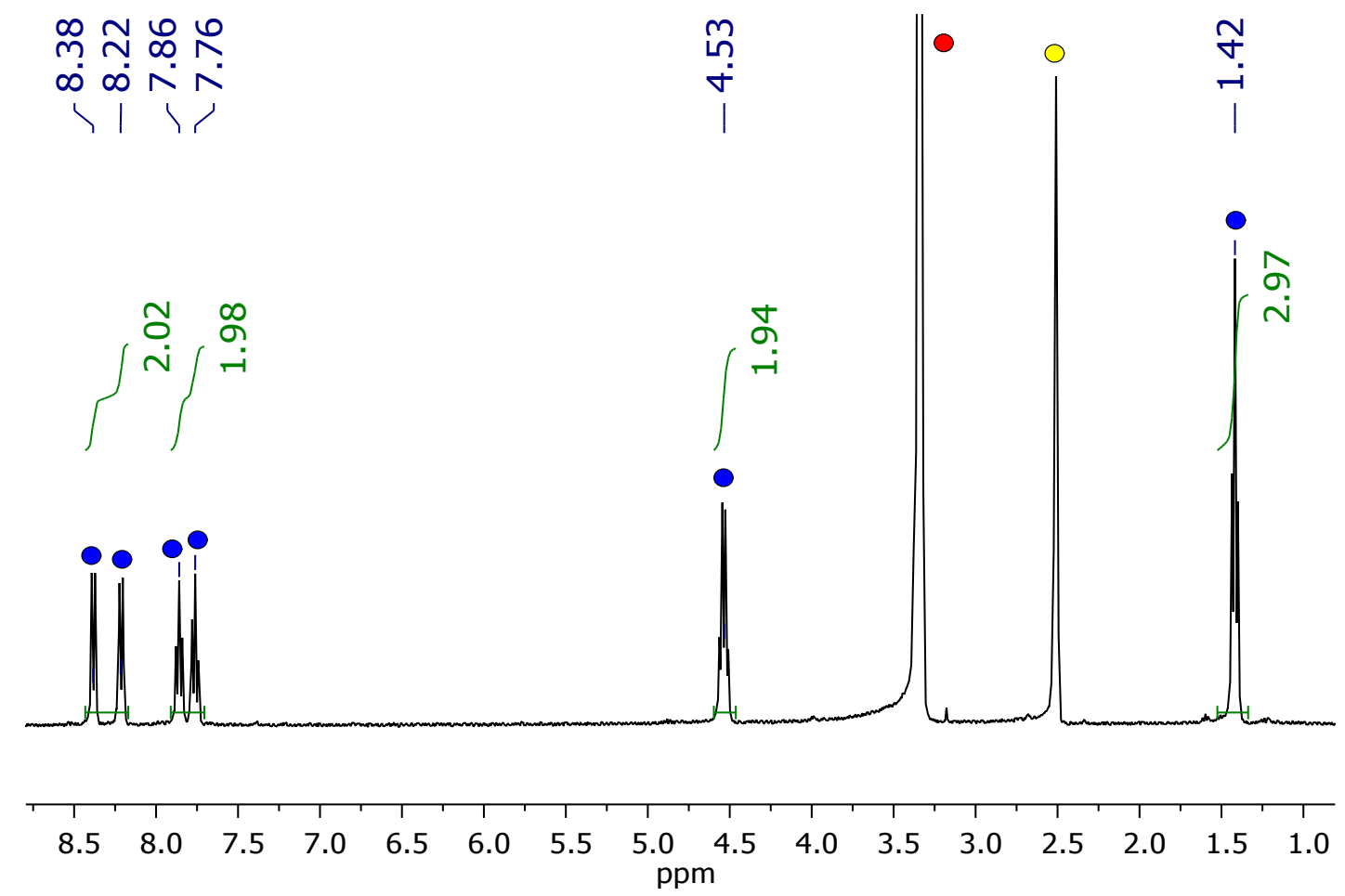

Figure S1. ${ }^{1} \mathrm{H}$ NMR (DMSO- $d_{6}, 400 \mathrm{MHz}$ ) spectrum of 2-azido-3-ethylbenzo[d]thiazol-3-ium tetrafluoroborate. Blue dots indicate product; yellow dot indicates NMR solvent ( $\delta 2.51-$ DMSO- $\mathrm{d}_{6}$ ); and red dot indicates $\mathrm{H}_{2} \mathrm{O}$ impurity $(\delta 3.33)$.

\section{Synthesis and characterization of 3,6-bis(diazo)cyclohexane-1,2,4,5-tetraone (3)}

3,6-bis(diazo)cyclohexane-1,2,4,5-tetraone was prepared according to a modified literature procedure. ${ }^{3}$ To a round-bottom flask charged with a solution of 2,5-hydroxy-p-benzoquinone (0.414 g, $2.95 \mathrm{mmol}$, Acros) in $\mathrm{MeOH}(10 \mathrm{~mL})$, 2-azido-3-ethylbenzo[d]thiazol-3-ium tetrafluoroborate $(2,1.75 \mathrm{~g}, 5.99 \mathrm{mmol})$ was added in one portion. Upon addition, the reaction mixture turned orange. This mixture was stirred at room temperature for four hours and subsequently cooled to $0{ }^{\circ} \mathrm{C}$ to afford a light yellow precipitate. The precipitate was collected by vacuum filtration and washed with cold $\mathrm{MeOH}(15 \mathrm{~mL})$, yielding a light yellow/tan solid. The solid was dried over $\mathrm{P}_{2} \mathrm{O}_{5}$ in vacuo for 1.5 hours, yielding the pure product $(440 \mathrm{mg}, 78 \%) .{ }^{13} \mathrm{C}$ NMR (DMSO- $d_{6}, 100$ MHz): $\delta$ 171.0, $\delta 92.0$ (Figure S2A). IR (ATR, $\mathrm{cm}^{-1}$ ): 2159 (CN stretch), 1635 (CO stretch), 1561 (N=N stretch) (Figure S2B). 
A

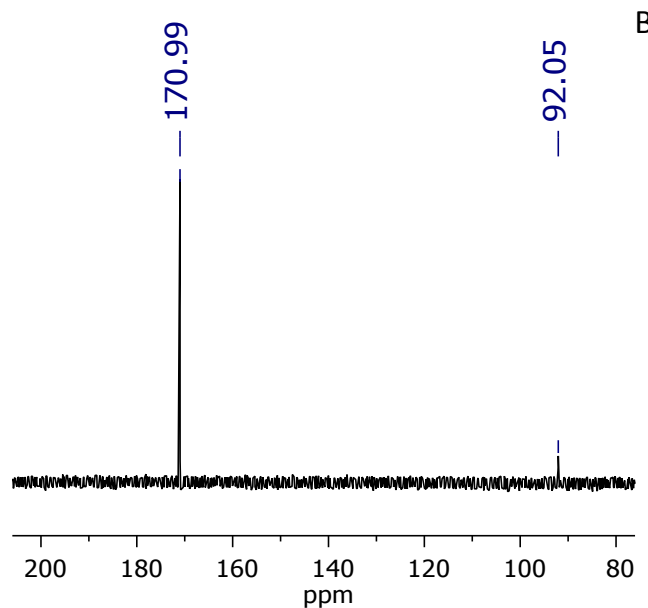

B

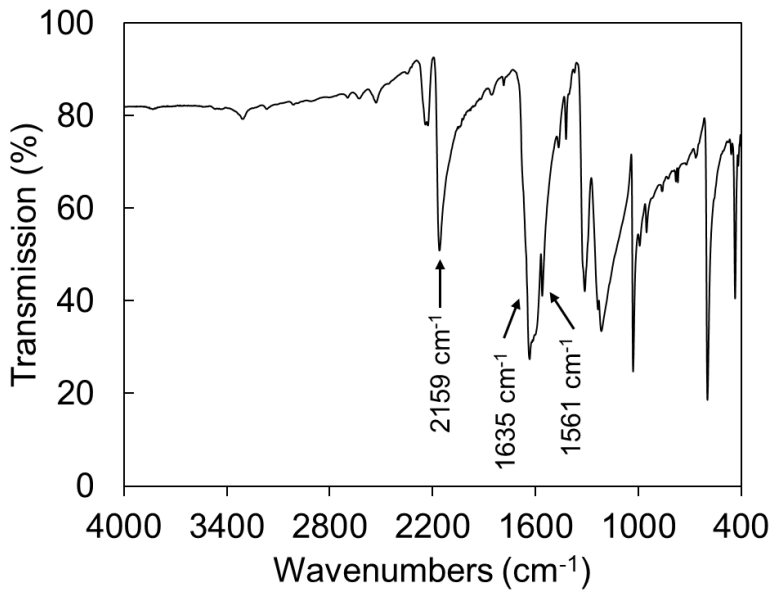

Figure S2. (A) ${ }^{13} \mathrm{C}$ NMR (DMSO- $d_{6}, 100 \mathrm{MHz}$ ) spectrum of 3,6-bis(diazo)cyclohexane-1,2,4,5-tetraone. (B) ATR-IR spectrum of 3,6-bis(diazo)cyclohexane-1,2,4,5-tetraone.

\section{Synthesis and characterization of benzo[1,2-d:4,5-d']bis([1,2,3]thiadiazole)-4,8-diol (4)}

Benzo[1,2-d:4,5-d']bis([1,2,3]thiadiazole)-4,8-diol was prepared according to modified literature procedure. ${ }^{3}$ To a three-neck flask charged with a solution of Lawesson's reagent (1.05 g, 2.60 mmol, Oakwood Chemical) in $\mathrm{CHCl}_{3}(7 \mathrm{~mL})$ was added 3,6-bis(diazo)cyclohexane-1,2,4,5-tetraone $(3,0.250 \mathrm{~g}, 1.30 \mathrm{mmol})$ in one portion. Upon addition, the reaction mixture turned yellow. The reaction mixture was stirred at $63{ }^{\circ} \mathrm{C}$ for 5 hours to afford a red solution. Water $(42 \mathrm{~mL})$ was added, and the reaction mixture was stirred for 2 days, over which time the $\mathrm{CHCl}_{3}$ evaporated. After stirring, the aqueous phase was an opaque yellow with a red precipitate. The water was decanted and the remaining mixture was dried under vacuum, yielding a red resin. The red resin was boiled in $\mathrm{MeOH}(5 \mathrm{~mL})$ for 10 minutes, and the solvent was decanted. The resin was washed several times with $\mathrm{MeOH}$ and isolated with a centrifuge. The remaining red solids were dried in air to yield the pure product (144 mg, 49\%). ${ }^{13} \mathrm{C}$ NMR (DMSO-d $6,100 \mathrm{MHz}$ ): $\delta$ 149.2, $\delta$ 137.2, $\delta$ 127.9. IR (ATR, $\mathrm{cm}^{-1}$ ): 3009 (O-H stretch), $1495,1429,1340,1283,1200,1019,848,720,687,613,539$. The ${ }^{13} \mathrm{C}$ NMR and IR spectra of the product match those reported in the literature. ${ }^{3}$

\section{Synthesis and characterization of benzo[1,2-d:4,5-d']bis([1,2,3]thiadiazole)-4,8-dione (NNS)}

NNS was prepared according to a modified literature procedure. ${ }^{3}$ A vial charged with finely ground benzo[1,2d:4,5-d']bis([1,2,3]thiadiazole)-4,8-diol (4, $140 \mathrm{mg}, 0.62 \mathrm{mmol})$ and $\mathrm{Na}_{2} \mathrm{Cr}_{2} \mathrm{O}_{7} \cdot 2 \mathrm{H}_{2} \mathrm{O}(737 \mathrm{mg}, 2.48 \mathrm{mmol})$ in glacial acetic acid $(9 \mathrm{~mL})$ was heated to $80{ }^{\circ} \mathrm{C}$ and stirred for 15 minutes. The green suspension was allowed to cool. The resulting tan precipitate was collected by vacuum filtration and washed with water $(10 \mathrm{~mL})$ and $\mathrm{CS}_{2}$ $(3 \times 0.7 \mathrm{~mL})$. The remaining tan solids were dried in vacuo at $50{ }^{\circ} \mathrm{C}$ to yield the pure product $(59 \mathrm{mg}, 46 \%)$. IR $\left(\right.$ ATR, $\left.\mathrm{cm}^{-1}\right): 1709,1686,1462,1347,1332,1260,1221,1056,858,825,733,652,619,539,527$. The IR spectrum of the product matches that reported in the literature. ${ }^{3}$ 
Scheme S2. Synthesis of NSN

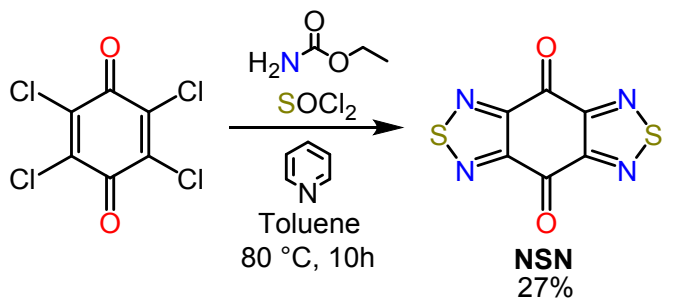

\section{Synthesis and characterization of benzo[1,2-c:4,5-c']bis([1,2,5]thiadiazole)-4,8-dione (NSN)}

NSN was prepared according to a modified literature procedure. ${ }^{4,5}$ To a three-neck flask charged with ethyl carbamate $(7.79 \mathrm{~g}, 87.45 \mathrm{mmol})$ in toluene $(80 \mathrm{~mL})$, pyridine $(40 \mathrm{~mL}, 500 \mathrm{mmol})$ was added in air to afford a white slurry. Under positive pressure of $\mathrm{N}_{2}$, freshly distilled thionyl chloride $(6.34 \mathrm{~mL}, 87.45 \mathrm{mmol})$ was added to afford a yellow slurry. The reaction mixture was allowed to stir at room temperature for one hour, after which p-chloranil $(2.5 \mathrm{~g}, 10.17 \mathrm{mmol})$ was added portionwise. The slurry slowly turned dark brown/black during addition and was allowed to stir overnight. After stirring, the solvent was removed in vacuo, and $3 \mathrm{M} \mathrm{HCl}(150$ $\mathrm{mL}$ ) was added to the dark resin. The mixture was collected by vacuum filtration to yield a tan solid, which was washed with $3 \mathrm{M} \mathrm{HCl}(3 \times 2 \mathrm{~mL})$ and a small amount of EtOH $(2 \times 2 \mathrm{~mL})$. The solid was air-dried for 30 minutes to yield a tan crude product $(0.953 \mathrm{~g}, 42 \%)$. The tan powder was washed with THF and dried in vacuo at $50{ }^{\circ} \mathrm{C}$ to yield the pure product. $(0.619 \mathrm{~g}, 27 \%) .{ }^{13} \mathrm{C}$ NMR (DMSO- $\left.d_{6}, 100 \mathrm{MHz}\right): \delta 169.3, \delta 158.4$. IR (ATR, $\left.\mathrm{cm}^{-1}\right): 1703,1449,1404,1058,856,842,745,663,510$. The ${ }^{13} \mathrm{C}$ NMR and IR spectra of the product match those reported in the literature. ${ }^{4,5}$ 

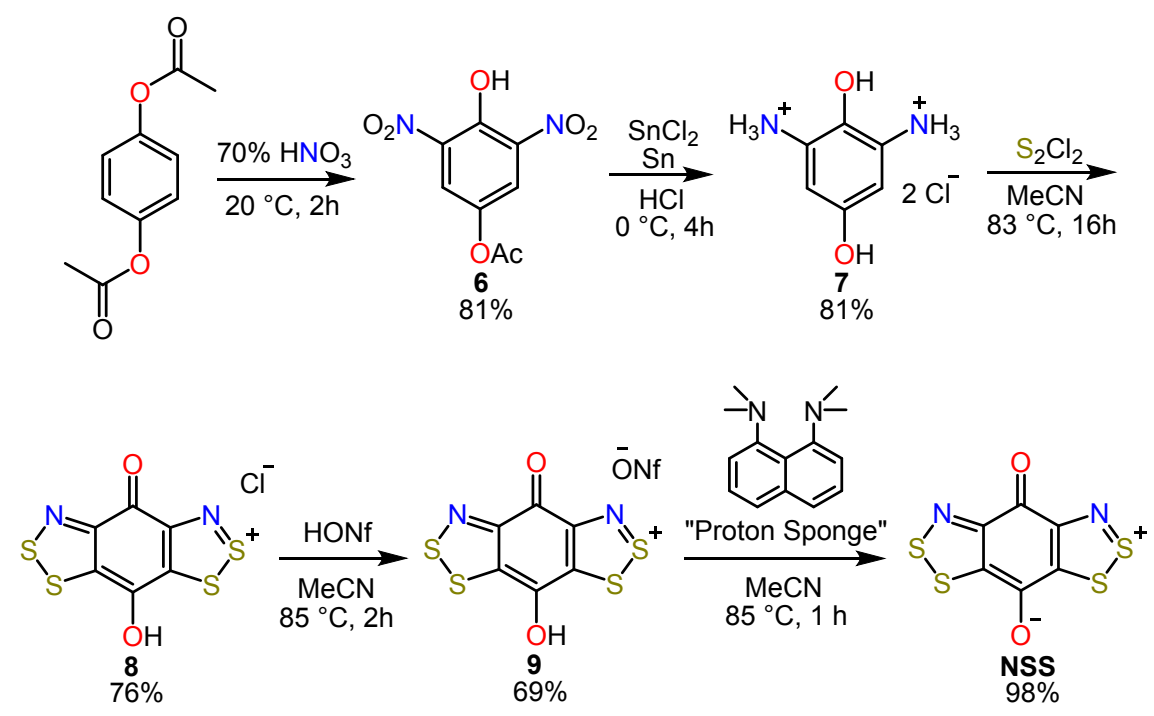

\section{Synthesis and characterization of 4-hydroxy-3,5-dinitrophenyl acetate (6)}

4-hydroxy-3,5-dinitrophenyl acetate was prepared according to a modified literature procedure. ${ }^{6,7}$ To a roundbottom flask containing $70 \% \mathrm{HNO}_{3}(50 \mathrm{~mL})$ at $0{ }^{\circ} \mathrm{C}$ was added 1,4-diacetoxybenzene $(5 \mathrm{~g}, 25.8 \mathrm{mmol}$, TCI America) portionwise. Upon addition, the slurry gradually turned yellow. After addition, the flask was capped and the reaction mixture was allowed to warm to $20^{\circ} \mathrm{C}$ and stir for 2.5 hours. After stirring, the reaction mixture became a bright orange suspension with yellow solids and orange vapor. The reaction mixture was poured over ice and filtered, yielding a bright yellow powder that was recrystallized in 200 proof EtOH to yield bright yellow crystals. The yellow crystals were washed with ether to yield the pure product $(2.346 \mathrm{~g}, 38 \%) .{ }^{1} \mathrm{H} \mathrm{NMR}\left(\mathrm{CDCl}_{3}\right.$, $400 \mathrm{MHz}): \delta 11.34(\mathrm{~s}, 1 \mathrm{H}), \delta 8.17(\mathrm{~s}, 2 \mathrm{H}), \delta 2.38(\mathrm{~s}, 3 \mathrm{H})$. The ${ }^{1} \mathrm{H}$ NMR spectrum of the product matches that reported in the literature. 6,7

\section{Synthesis and characterization of 2,5-dihydroxybenzene-1,3-diaminium chloride (7)}

2,5-dihydroxybenzene-1,3-diaminium chloride was prepared according to modified literature procedure. ${ }^{7}$ To a round-bottom flask charged with 4-hydroxy-3,5-dinitrophenyl acetate $(6,2.33 \mathrm{~g}, 9.62 \mathrm{mmol})$ in concentrated $\mathrm{HCl}(43 \mathrm{~mL})$ was added $\mathrm{SnCl}_{2}(1.82 \mathrm{~g}, 9.62 \mathrm{mmol})$. The reaction mixture was cooled to $0{ }^{\circ} \mathrm{C}$, and tin powder (3.43 g, $28.87 \mathrm{mmol}$ ) was added portionwise over 15 minutes. The reaction mixture was stirred for 4 hours and allowed to warm to room temperature. To the resulting mixture was added concentrated $\mathrm{HCl}(21 \mathrm{~mL})$. After 30 minutes, the precipitate was filtered and washed with concentrated $\mathrm{HCl}$, yielding an off-white solid. The solids were recrystallized from a 5:1 mixture of concentrated $\mathrm{HCl}$ :water $(380 \mathrm{~mL})$ to yield the pure product as offwhite needle-like crystals (1.65 mg, 80\%). IR (ATR, $\left.\mathrm{cm}^{-1}\right)$ 3153, 2817, 2624, 2593, 1901, 1729, 1587, 1556, $1523,1510,1473,1342,1323,1271,1209,1145,1097,1072,978,851,854,793,705,624,561,548,509,466$. The IR spectrum of the product matches that reported in the literature. ${ }^{7}$ 
Synthesis and characterization of 8-hydroxy-4-oxo-4H-benzo[1,2-d:5,4-d']bis([1,2,3]dithiazole)-2-ium chloride (8)

8-hydroxy-4-oxo-4H-benzo[1,2-d:5,4-d']bis([1,2,3]dithiazole)-2-ium chloride was prepared according to modified literature procedure. ${ }^{7}$ A Schlenk flask was charged with 2,5-dihydroxybenzene-1,3-diaminium chloride $(7,1.00 \mathrm{~g}, 4.69 \mathrm{mmol})$ suspended in $\mathrm{MeCN}(100 \mathrm{~mL})$. The flask was taken out of the glovebox along with a septum-capped vial of $\mathrm{S}_{2} \mathrm{Cl}_{2}$. The flask and vial were placed under a positive pressure of $\mathrm{N}_{2}$, and $\mathrm{S}_{2} \mathrm{Cl}_{2}$ $\left(3.0 \mathrm{~mL}, 37.55 \mathrm{mmol}\right.$ ) was added to the reaction mixture. Upon addition of $\mathrm{S}_{2} \mathrm{Cl}_{2}$, the reaction mixture gradually changed from off-white to forest green to black over 15 minutes. The reaction mixture was refluxed overnight, resulting in a golden brown solution with a metallic gold film on the walls of the flask. The reaction was allowed to cool to room temperature before being taken back into the glovebox. The black precipitate was collected by vacuum filtration and washed with MeCN $(40 \mathrm{~mL})$ and warm DCM $(20 \mathrm{~mL})$. The filtered black powder was transferred to a vial and suspended in toluene $(40 \mathrm{~mL})$. The vial was sealed and heated to $110{ }^{\circ} \mathrm{C}$ for $\sim 10 \mathrm{~min}$. While the mixture was hot, the black powder was collected again by vacuum filtration and washed with hot toluene $(3 \times 10 \mathrm{~mL})$. The resulting bronze-flecked deep black powder was dried in vacuo to yield the pure product (955 mg, 69\%). IR (ATR, $\left.\mathrm{cm}^{-1}\right): 1668,1596,1491,1458,1314,1233,1151,1087,842,770,737,665$, $636,597,496,481,473,446$. The IR spectrum of the product matches that reported in the literature. ${ }^{7}$

\section{Synthesis and characterization of 8-hydroxy-4-oxo-4H-benzo[1,2-d:5,4-d']bis([1,2,3]dithiazole)-2-ium nonaflate (9)}

8-hydroxy-4-oxo-4H-benzo[1,2-d:5,4-d']bis([1,2,3]dithiazole)-2-ium nonaflate was prepared according to modified literature procedure. ${ }^{7,8}$ A Schlenk flask was charged with 8-hydroxy-4-oxo-4H-benzo[1,2-d:5,4d']bis([1,2,3]dithiazole)-2-ium chloride (8, $950 \mathrm{mg}, 3.2 \mathrm{mmol})$ suspended in $\mathrm{MeCN}$ (20 mL). Neat nonafluorobutane-1-sufonic acid (HONf) (1.03 mL, $6.21 \mathrm{mmol}$, TCI America) was added to afford a deep blue slurry that was refluxed for 2 hours. The reaction mixture was allowed to cool to room temperature, and DCM (30 mL) was added. The reaction mixture was further cooled in the freezer overnight. The resulting brown microcrystalline solid was collected by vacuum filtration and recrystallized in acetic acid $(300 \mathrm{~mL})$ to yield a microcrystalline solid. The bronze microcrystals were collected by vacuum filtration, washed with acetic acid, and dried in air to yield the pure product (1.23 g, 69\%). IR (ATR, $\left.\mathrm{cm}^{-1}\right): 1682,1513,1456,1441,1437,1353$, $1328,1252,1223,1141,1134,1097,1062,1017,854,803,772,739,698,659,599,523,494,475$. The IR spectrum of the product matches that reported in the literature. ${ }^{7}$ 
NSS was prepared according to a modified literature procedure. ${ }^{7}$ A Schlenk flask was charged with -hydroxy4-oxo-4H-benzo[1,2-d:5,4-d']bis([1,2,3]dithiazole)-2-ium nonaflate $(\mathbf{8}, 600 \mathrm{mg}, 1.07 \mathrm{mmol})$ suspended in MeCN (90 mL). A solution of Proton Sponge (275 mg, $1.28 \mathrm{mmol}$, CombiBlocks) in MeCN (15 mL) was prepared in a vial. Both vessels were taken out of the glovebox and the Schlenk flask was heated to $80{ }^{\circ} \mathrm{C}$ with stirring for 10 minutes. Under positive pressure of $\mathrm{N}_{2}$, the solution of Proton Sponge was added dropwise over 10 minutes, and the mixture was refluxed for 1 hour. After refluxing, the mixture was allowed to cool to room temperature. The reaction flask was brought back into the glovebox and the mixture was filtered and washed with $\mathrm{MeCN}$ to yield a dark blue-black powder (259 mg, 93\%). IR (ATR, $\left.\mathrm{cm}^{-1}\right)$ 1655, 1645, 1553, 1480, 1427, $1421,1357,1318,1301,1283,1163,1091,1050,970,850,832,776,731,687,669,499,477,457,434$. The IR spectrum of the product matches that reported in the literature. ${ }^{7}$ 


\section{Electrochemical Measurements}

\section{Solution Phase Cyclic Voltammetry}

Solution phase cyclic voltammetry (CV) experiments were carried out using a three-electrode cell, consisting of a glassy carbon working electrode $\left(0.07 \mathrm{~cm}^{2}, \mathrm{CH}\right.$ Instruments), a $\mathrm{Ag} / \mathrm{AgNO}_{3}$ reference electrode $(\mathrm{CH}$ Instruments) with $0.01 \mathrm{M} \mathrm{AgNO}_{3}$ in $\mathrm{MeCN}$, and a platinum wire counter electrode $(7.5 \mathrm{~cm}, \mathrm{BASi})$. Solution $\mathrm{CV}$ experiments were performed under an atmosphere of $\mathrm{N}_{2}$ with degassed electrolyte solutions of $0.1 \mathrm{M}$ $\mathrm{TBAClO}_{4}$ in NMP containing $1 \mathrm{mM}$ NNS, NSN, or NSS at a scan rate of $100 \mathrm{mV} \mathrm{s}^{-1}$.

\section{Solid State Cyclic Voltammetry}

Solid-state CV experiments were carried out using a two-electrode coin-type cell, consisting of a cathode of NNS, NSN, or NSS and an anode of Li metal (see Battery Testing). Solid-state CV experiments were performed at a scan rate of $1 \mathrm{mV} \mathrm{s}^{-1}$ after an initial rest period of two hours.
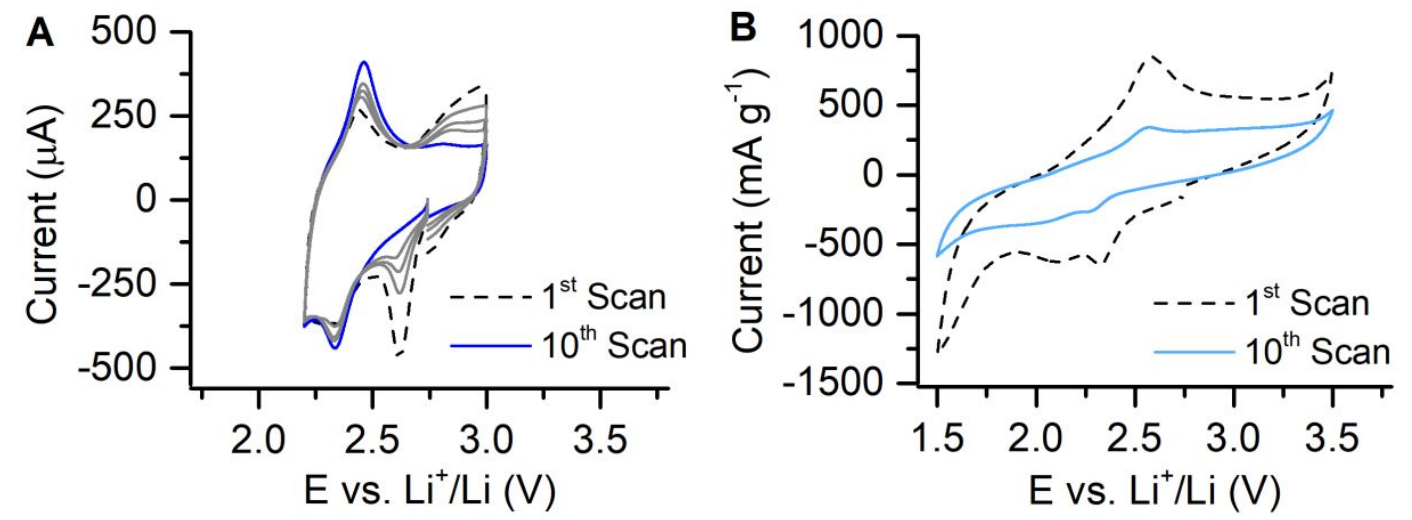

Figure S3. Solid-state CVs of NSS depicting (A) the shift of the NSS redox potentials over the first ten scans with a voltage window of $3.0 \mathrm{~V}-2.2 \mathrm{~V}$ and (B) the decrease in current between the first scan and the tenth scan of NSS after expanding the voltage window to $3.5 \mathrm{~V}-1.5 \mathrm{~V}$. 


\section{Potentio-electrochemical Impedance Spectroscopy (PEIS)}

PEIS measurements of coin-type cells with NNS, NSN, or NSS cathodes were conducted with a voltage amplitude of $10 \mathrm{mV}$ and a frequency range of $200000 \mathrm{~Hz}-0.1 \mathrm{~Hz}$. The first measurement was acquired on fresh cells before cycling. Following measurements were performed immediately after a $\mathrm{CV}$ scan at $1 \mathrm{mV} \mathrm{s}^{-1}$ to monitor changes in impedance over time (Figure S3 and S4).

Resistance values were obtained by fitting the potentio-electrochemical impedance data to an equivalent circuit, shown in Figure $\mathrm{S} 3 \mathrm{C} . \mathrm{R}_{\mathrm{B}}, \mathrm{R}_{\mathrm{CT}}, \mathrm{R}_{\mathrm{INT}}, \mathrm{CPE}, \mathrm{W}_{\mathrm{O}}$, and $\mathrm{C}$ represent bulk resistance, charge transfer resistance, total internal resistance, constant phase element, Warburg impedance, and capacitor, respectively.

Li-ion diffusion coefficients were derived from Eq. (1):

$$
D_{L i}{ }^{+}=0.5\left(\frac{\mathrm{RT}}{\mathrm{AF}^{2} \sigma \mathrm{C}}\right)^{2}
$$

where $\mathrm{R}$ is the gas constant $\left(8.314 \mathrm{~J} \mathrm{~mol}^{-1} \mathrm{~K}^{-1}\right), \mathrm{T}$ is the temperature $(298.5 \mathrm{~K}), \mathrm{A}$ is the area of the electrode surface $\left(1.767 \mathrm{~cm}^{2}\right), \mathrm{F}$ is Faraday's constant $\left(9.65 \times 10^{4} \mathrm{C} \mathrm{mol}^{-1}\right), \mathrm{C}$ is the molar concentration of $\mathrm{Li}^{+}(0.001$ $\mathrm{mol} \mathrm{mL}^{-1}$ ), and $\sigma$ is the Warburg coefficient. The Warburg coefficient $\sigma$ can be obtained from Eq. (2):

$$
\mathrm{Z}_{\mathrm{RE}}=\mathrm{R}_{\mathrm{B}}+\mathrm{R}_{\mathrm{CT}}+\sigma \omega^{-0.5}
$$

where $\sigma$ is the slope for the plot of $Z_{\mathrm{RE}}$ vs. the reciprocal root square of the lower angular frequencies $\left(\omega^{-0.5}\right)$. The obtained $\sigma$ for fresh cells of NNS, NSN, and NSS is 14.1, 11.2, and 15.4, respectively. Consequently, fresh cells of NNS, NSN, and NSS have $D_{\mathrm{Li}+}$ of $5.72 \times 10^{-11} \mathrm{~cm}^{2} \mathrm{~s}^{-1}, 9.06 \times 10^{-11} \mathrm{~cm}^{2} \mathrm{~s}^{-1}$, and $4.62 \times 10^{-11} \mathrm{~cm}^{2} \mathrm{~s}^{-1}$, respectively. Figure S4D shows the change in $\mathrm{D}_{\mathrm{Li}+}$ for NSS over ten scans.
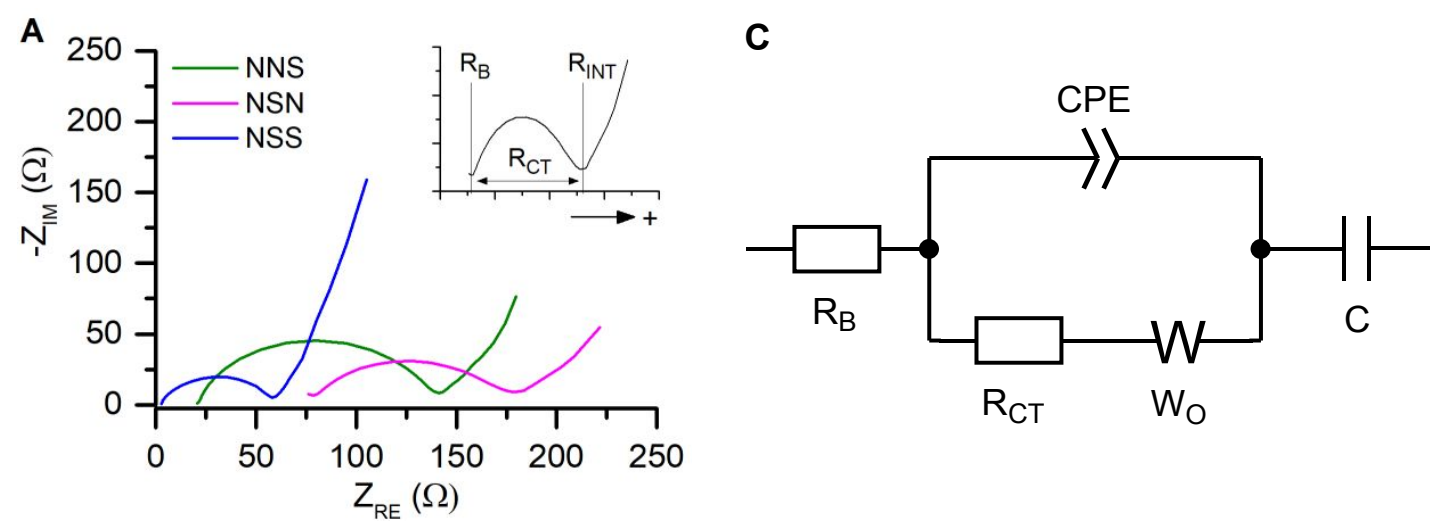

B

\begin{tabular}{|l|c|c|c|c|c|c|}
\cline { 2 - 7 } \multicolumn{1}{c|}{} & $\mathbf{R}_{\mathbf{B}}(\mathbf{\Omega})$ & $\mathbf{R}_{\mathbf{C T}}(\mathbf{\Omega})$ & $\mathbf{C P E}\left(\mathbf{F ~ S} \mathbf{( A - 1 )}^{-1}\right)$ & $\mathbf{A}$ & $\mathbf{W}_{\mathbf{O}}\left(\mathbf{\Omega} \mathbf{S ~}^{-0.5}\right)$ & $\mathbf{C}(\mathbf{F})$ \\
\hline NNS & 20.80 & 116.80 & $9.05 \times 10^{-6}$ & 0.837 & 35.02 & 0.05041 \\
NSN & 87.78 & 103.3 & $30.63 \times 10^{-6}$ & 0.669 & 26.98 & 0.50780 \\
NSS & 2.37 & 54.29 & $15.51 \times 10^{-6}$ & 0.792 & 34.55 & 0.01391 \\
\hline
\end{tabular}

Figure S4. (A) Nyquist plots of fresh cells with NNS, NSN, and NSS cathodes and (B) corresponding resistance values. (C) The equivalent circuit used for fitting PEIS data. 

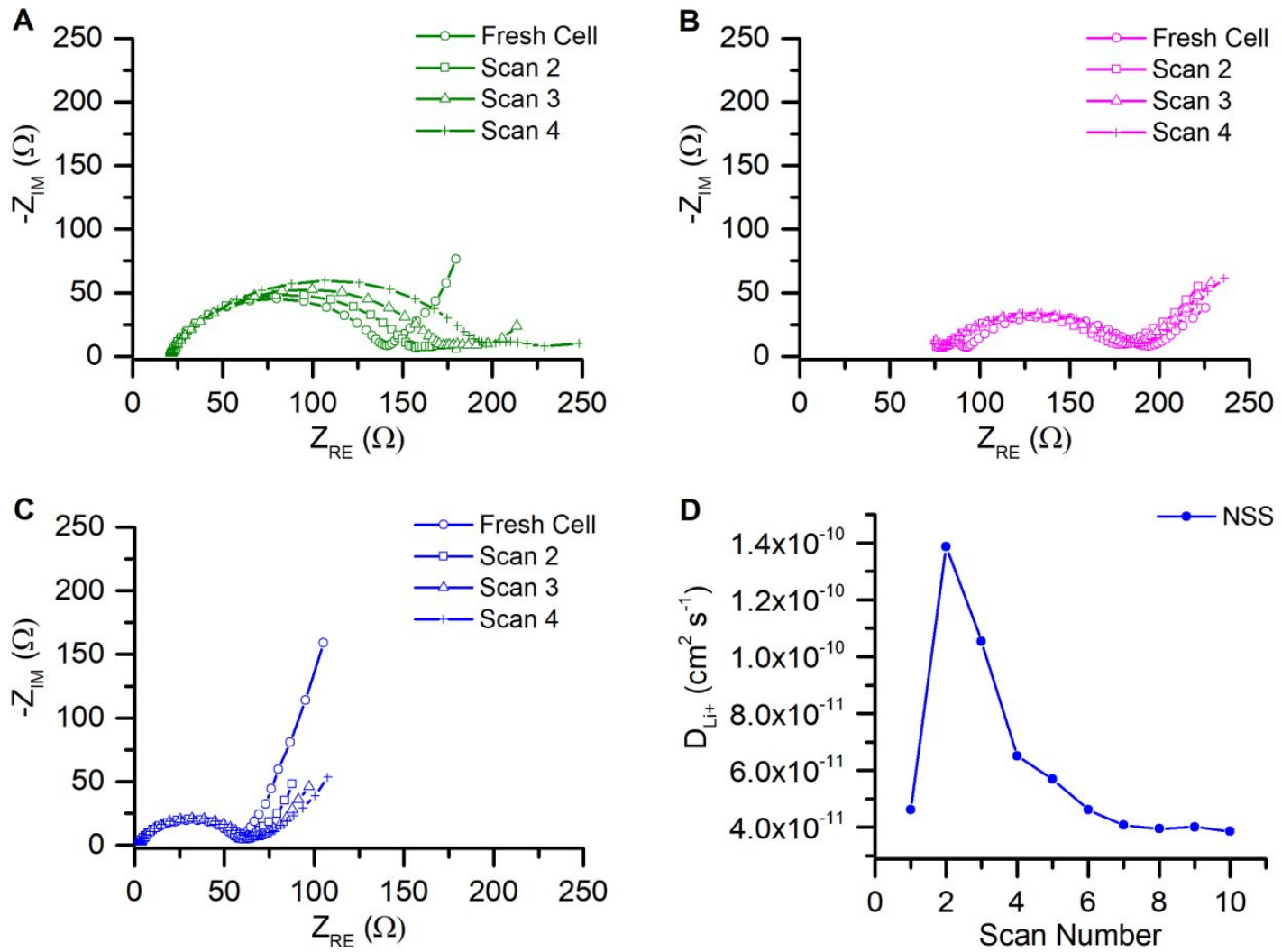

Figure S5. Nyquist plots of the first four scans with (A) NNS, (B) NSN, and (C) NSS cathodes. (D) The plot of derived $\mathrm{Li}^{+}$diffusion coefficients of NSS after each CV scan for ten scans. 


\section{Battery Testing}

\section{Electrode Fabrication}

Electrode dry mixtures were prepared by mixing powders of NNS, NSN, or NSS with conductive carbon (SuperP) and polyvinylidene fluoride (PVDF) binder in a 50:40:10 weight ratio using a mortar and pestle. Electrode slurries were prepared by adding $N$-methylpyrrolidinone (NMP) to the dry mixture, vortexing for 1 minute, and sonicating for at least 30 minutes until a smooth ink was obtained. The inks were cast onto aluminum foil using the doctor-blade method (average mass loading density: $c a .0 .67 \mathrm{mg} \mathrm{cm}^{-2}$ ), dried in air overnight, and further dried in a vacuum oven at $50{ }^{\circ} \mathrm{C}$ overnight. After cutting the electrodes into $15 \mathrm{~mm}$ discs, they were dried again under vacuum at $50{ }^{\circ} \mathrm{C}$ for at least 2 hours, and taken into an argon glovebox while still under vacuum.

\section{Coin Cell Assembly}

Coin-type cells were assembled in an argon glovebox with NNS, NSN, or NSS as the cathode, 1 M LiTFSI (lithium bis(trifluoromethanesulfonyl)imide) and 0.2 $\mathrm{M} \mathrm{LiNO}_{3}$ in 50:50 dimethoxyethane (DME) and dioxolane (DOL) as the electrolyte, Celgard as the separator, and Li metal as the anode. Coin cells were assembled bottom to top using materials purchased from Gelon: coin cell bottom, cathode pellet, $50 \mu \mathrm{L}$ electrolyte, separator, 50 $\mu \mathrm{L}$ electrolyte, $\mathrm{Li}$ anode, stainless steel current collector, wave/conical washer, coin cell top with gasket. Coin cells were crimped in a Gelon GN-CCM20 coin cell crimper at 900 psi and used for battery testing after a rest period of 2 hours.

\section{Galvanostatic Charge/Discharge Cycling}

Coin-type cells with NNS, NSN, or NSS cathodes were subjected to galvanostatic cycling using an automated testing system with lower voltage limits of $1.8 \mathrm{~V}\left(v s . \mathrm{Li}^{+} / \mathrm{Li}\right)$ and upper voltage limits selected based on solidstate CV studies (vide supra). The currents for galvanostatic measurements were calculated based on the theoretical specific capacity of each compound. 
A

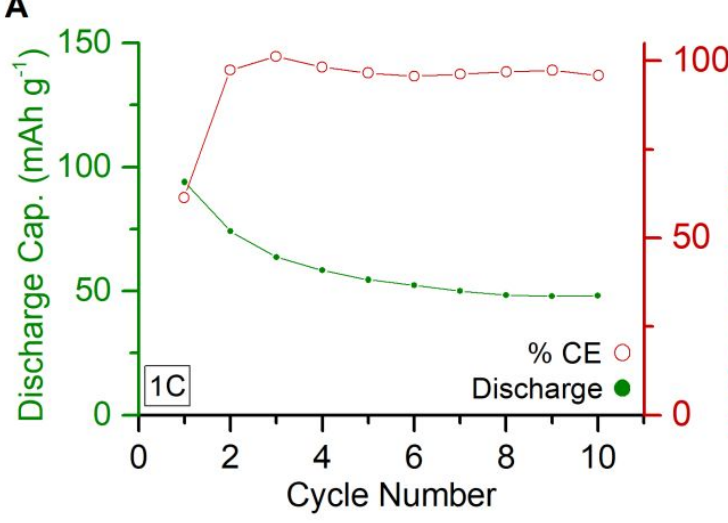

B
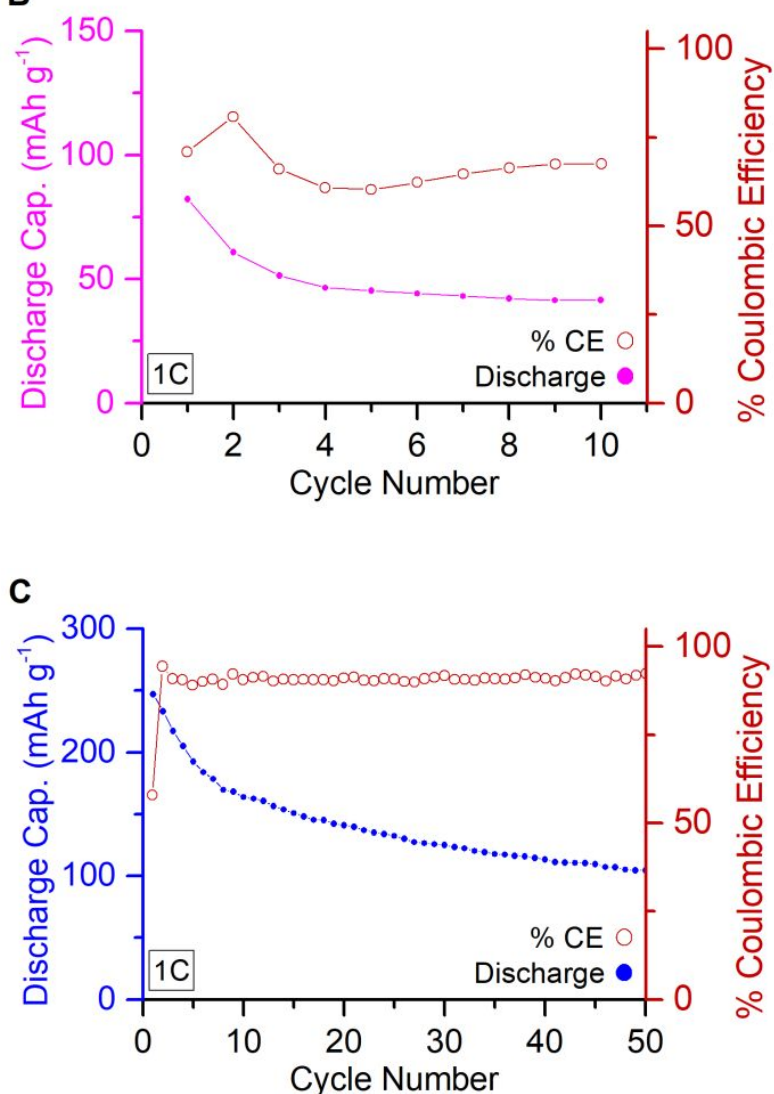

D

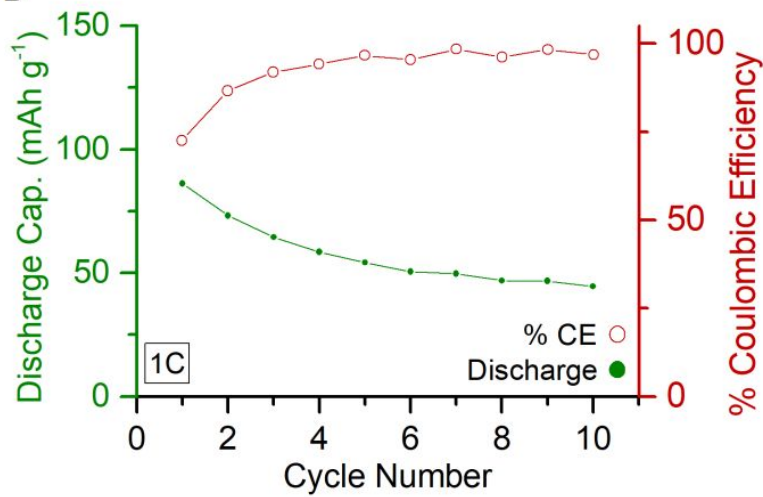

E

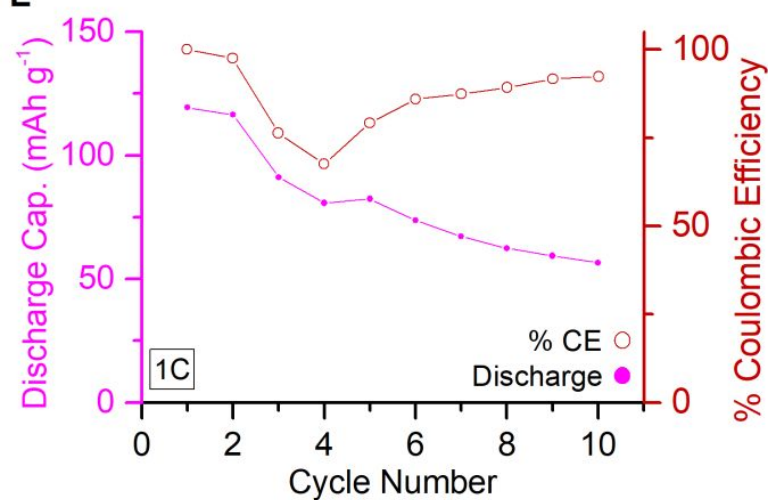

$\mathbf{F}$

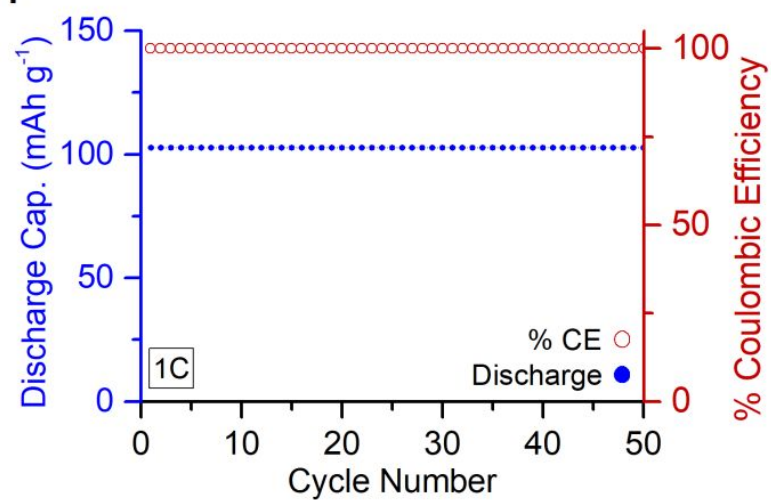

Figure S6. Galvanostatic cycling plots and corresponding coulombic efficiencies at a two electron per molecule level for (A) NNS at $1 \mathrm{C}\left(240 \mathrm{~mA} \cdot \mathrm{g}^{-1}\right)$, (B) NSN at $1 \mathrm{C}\left(240 \mathrm{~mA} \cdot \mathrm{g}^{-1}\right)$, and (C) NSS at $1 \mathrm{C}$ $\left(206 \mathrm{mAh} \bullet \mathrm{g}^{-1}\right)$. Galvanostatic cycling plots and corresponding coulombic efficiencies at a one electron per molecule level for (D) NNS at $1 \mathrm{C}\left(120 \mathrm{~mA} \bullet \mathrm{g}^{-1}\right)$, (B) NSN at $1 \mathrm{C}\left(120 \mathrm{~mA} \bullet \mathrm{g}^{-1}\right)$, and (C) NSS at $1 \mathrm{C}$ $\left(103 \mathrm{mAh} \bullet \mathrm{g}^{-1}\right)$. 

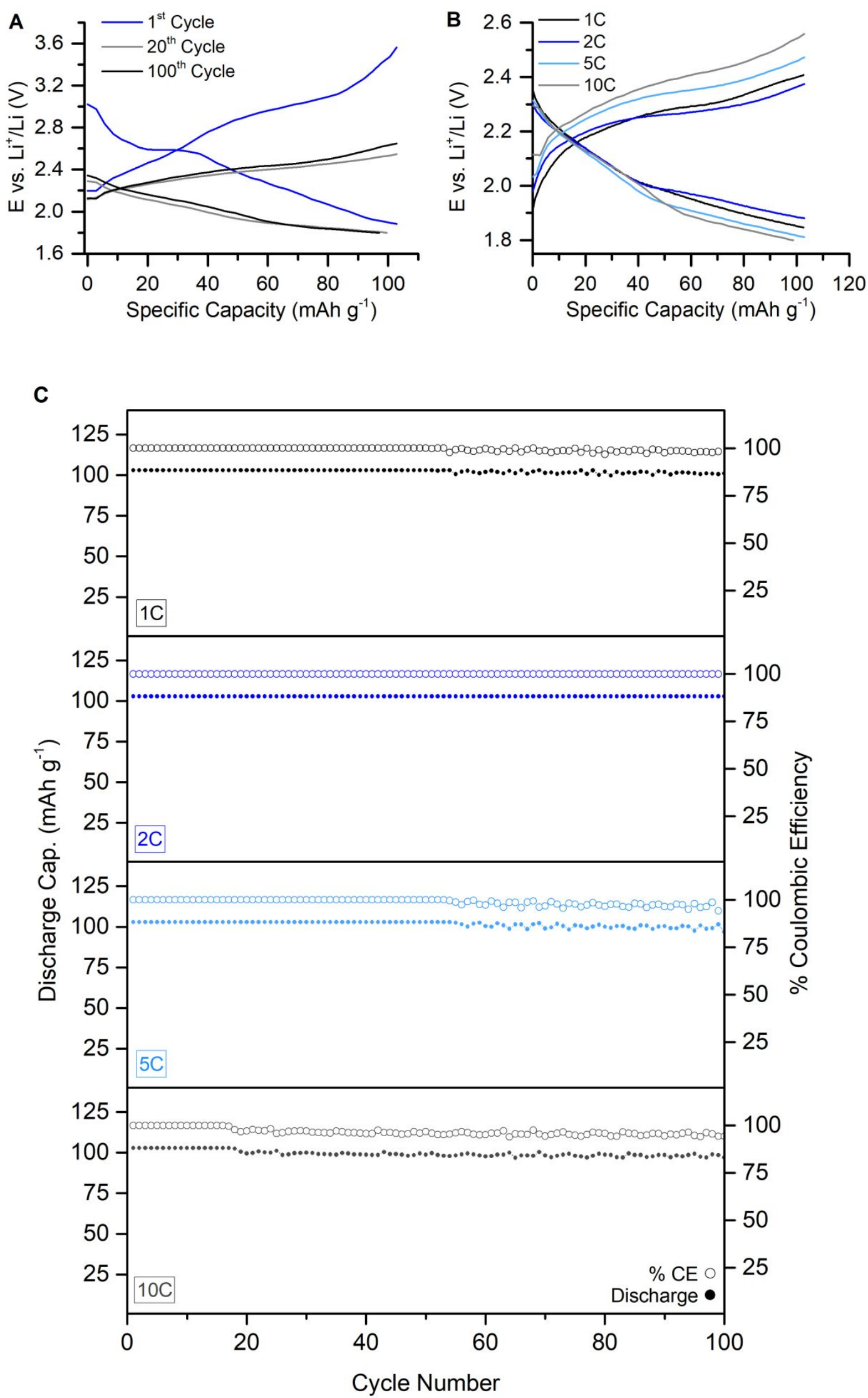

Figure S7. Plots of voltage vs. specific capacity (A) the $1^{\text {st }}, 20^{\text {th }}$, and $100^{\text {th }}$ cycles of NSS at $10 \mathrm{C}(1030$ $\left.\mathrm{mA} \cdot \mathrm{g}^{-1}\right)$, and (B) the NSS discharge profile of every $50^{\text {th }}$ cycle at various cycling rates from $1 \mathrm{C}$ to 10C. (C) Galvanostatic cycling plots of NSS at various cycling rates from 1C to 10C. 


\section{Ex-situ Analysis}

\section{Coin Cell Disassembly}

Within 24 hours after cycling, the battery was taken into an Ar glovebox and disassembled on an MSK-110 coin cell crimping machine equipped with a disassembly die set. Pictures of the electrodes and separators were taken upon disassembly. To prepare the cathodes for ex-situ analysis, they were washed with DME $(3 \times 50 \mu \mathrm{L})$ and dried in vacuo for at least 30 minutes.

\section{Raman Spectroscopy}

Raman spectra of NNS, NSN, and NSS were measured under an inert atmosphere using a $50 \times$ or $10 \times$ microscope lens and a $633 \mathrm{~nm}$ laser beam at $50 \%$ or $10 \%$ laser power. Spectra were measured from $100 \mathrm{~cm}^{-1}$ to $2000 \mathrm{~cm}^{-1}$ at 3-5 different spots on each cathode to ensure uniformity. For NNS and NSN, "after cycling" spectra were measured after two cycles in a fully charged (3.5 V) state. For NSS, " after cycling” spectra were measured after 50 cycles in a fully charged $(2.8 \mathrm{~V})$ state. 


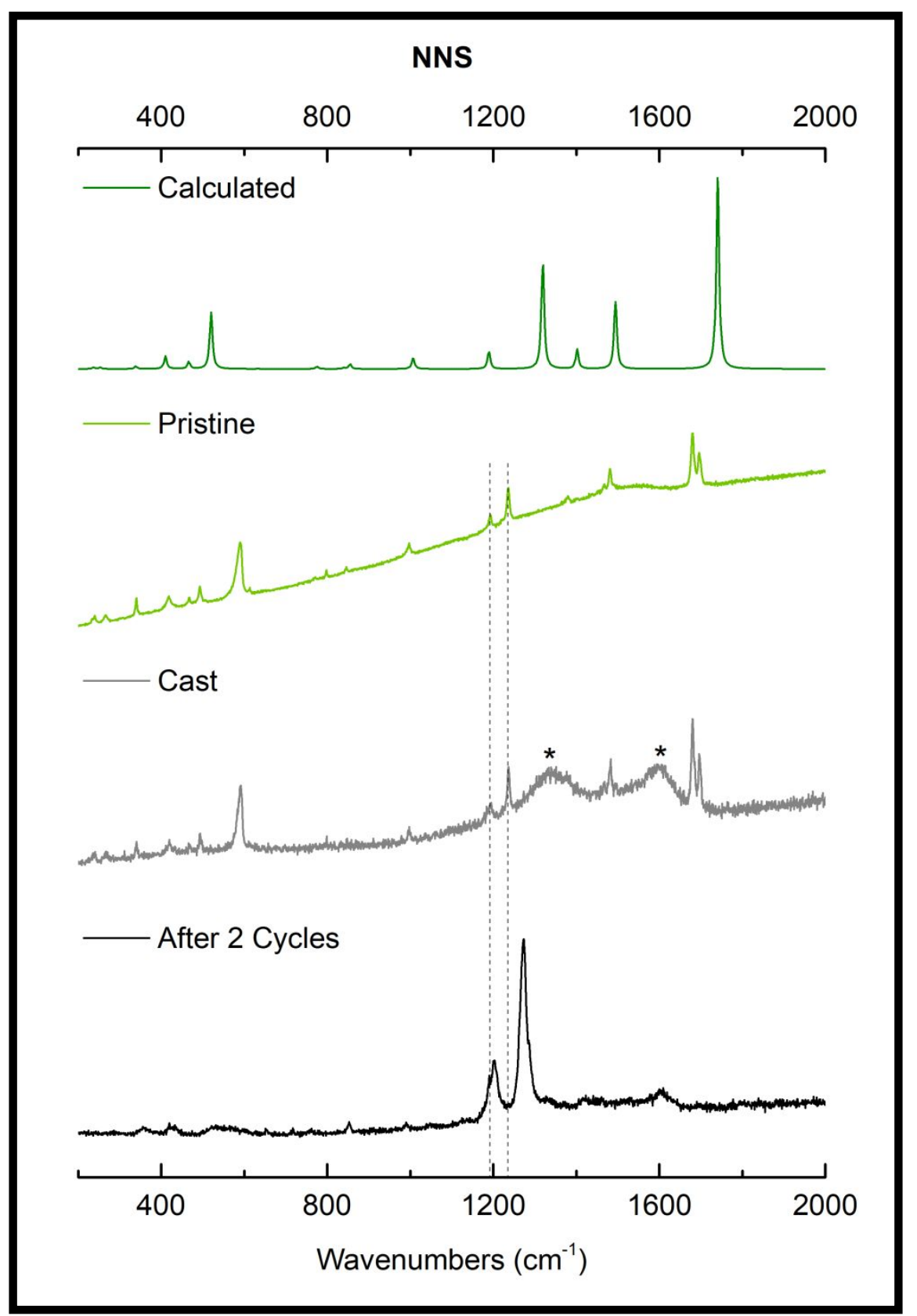

Figure S8. Calculated and experimental Raman spectra of NNS. Asterisks mark the broad bands of the conductive carbon additive, Super $\mathrm{P}$, at $1339 \mathrm{~cm}^{-1}$ and $1605 \mathrm{~cm}^{-1}$. Dotted lines reveal a shift in the two N-N stretches to higher wavenumbers after cycling. 


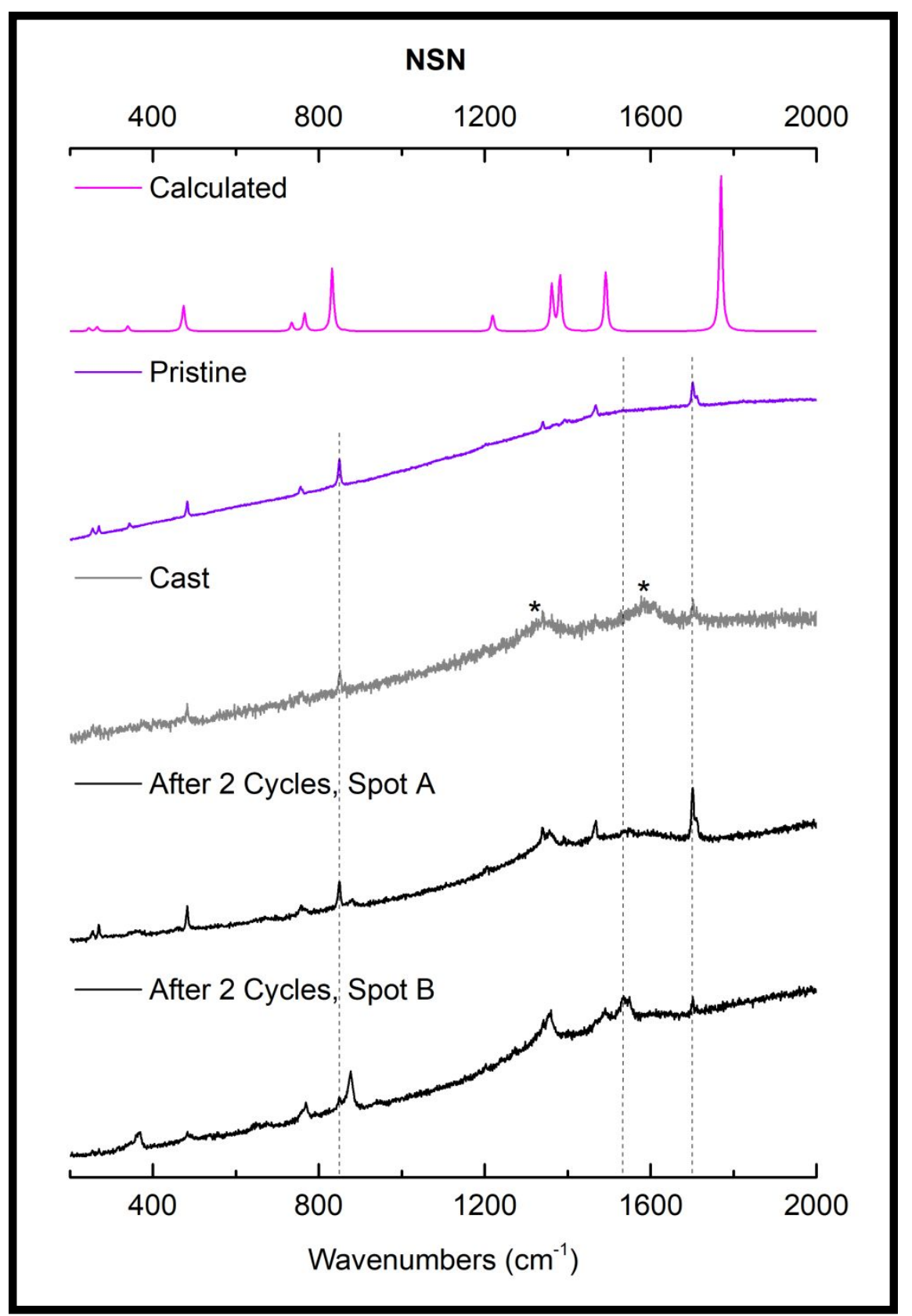

Figure S9. Calculated and experimental Raman spectra of NSN. Asterisks mark the broad bands of the conductive carbon additive, Super P, at $1339 \mathrm{~cm}^{-1}$ and $1605 \mathrm{~cm}^{-1}$. Dotted lines reveal that the spectrum labelled "After 2 Cycles, Spot A" matches those taken before cycling, and the spectrum labelled "After 2 Cycles, Spot B" exhibits a shift of the $\mathrm{C}=\mathrm{O}$ and $\mathrm{N}-\mathrm{S}$ stretching frequencies toward lower and higher wavenumbers (1535 $\mathrm{cm}^{-1}$ and $877 \mathrm{~cm}^{-1}$, respectively), indicating formation of $\mathbf{N S N}^{2-}$. 


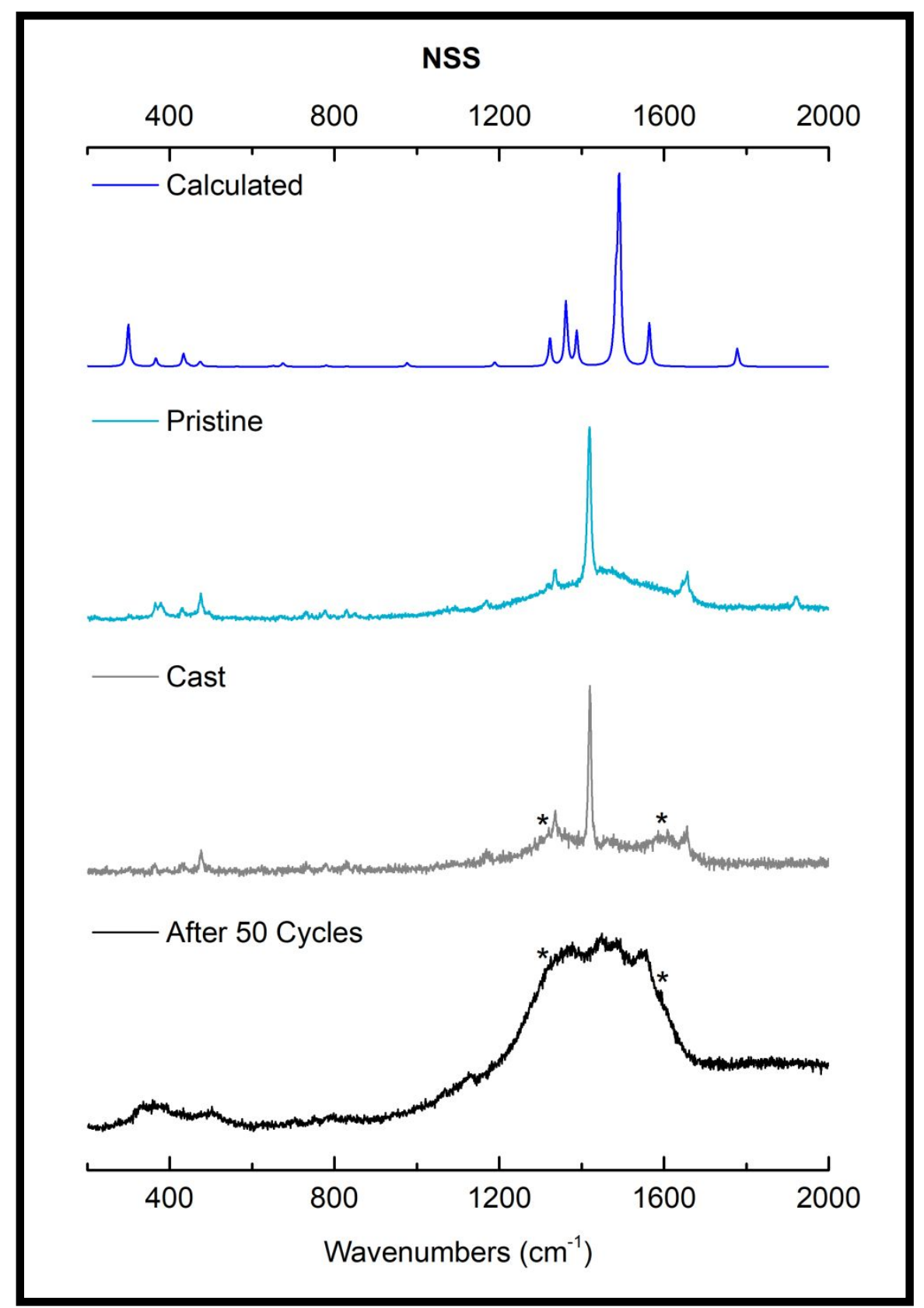

Figure S10. Calculated and experimental Raman spectra of NSS. Asterisks mark the broad bands of the conductive carbon additive, Super $\mathrm{P}$, at $1339 \mathrm{~cm}^{-1}$ and $1605 \mathrm{~cm}^{-1}$. 


\section{Scanning Electron Microscopy}

Micrographs were acquired with a $5 \mathrm{keV}$ or $10 \mathrm{keV}$ beam voltage and $0.40 \mathrm{nA}$ beam current in OptiPlan mode.

Samples were prepared in a glovebox on conductive carbon tape substrate and were quickly transferred to the high vacuum chamber to minimize exposure to air.

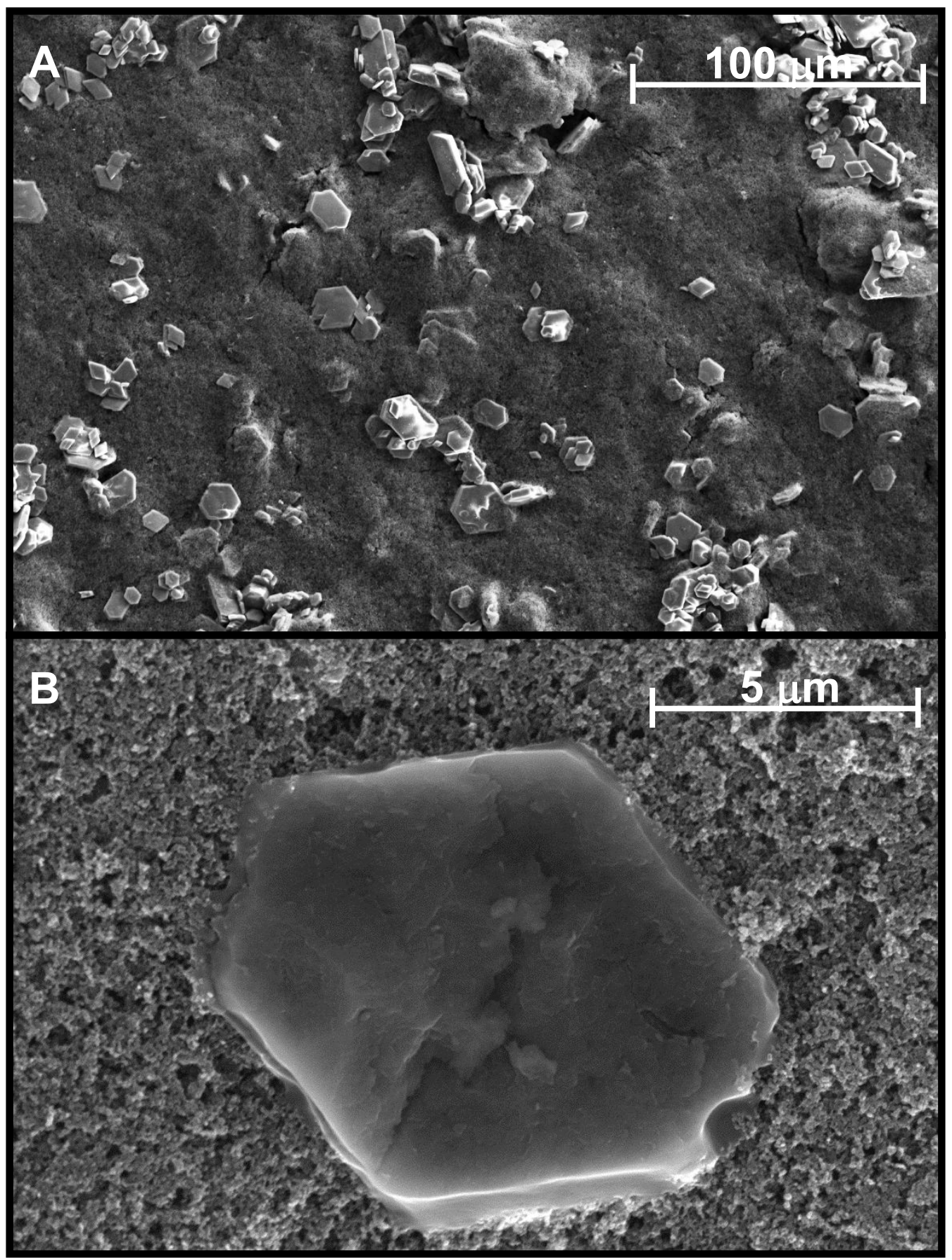

Figure S11. Micrographs of pristine NNS electrode showing (A) a wide-field view of the electrode surface with multiple hexagonally-shaped particles surrounded by the conductive carbon additive, Super P, and (B) a single hexagonal particle with rough surface morphology surrounded by Super P. 


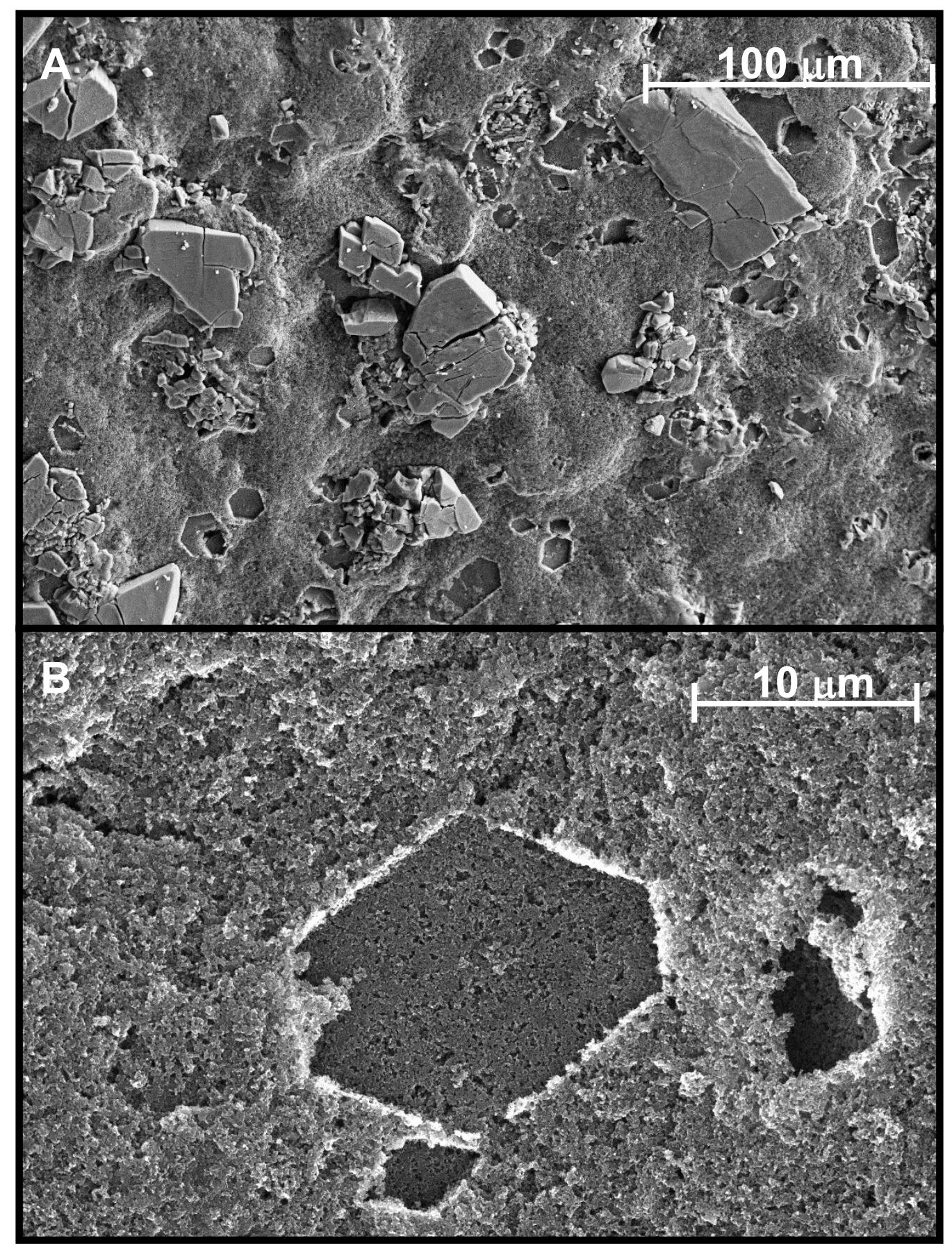

Figure S12. Micrographs of NNS electrode after two cycles showing (A) a wide-field view of the electrode surface with large and multiple hexagonally-shaped holes in the Super P, and (B) a single hexagonally-shaped hole in the Super P where a hexagonal NNS particle once resided. Based on electrochemical performance and Raman studies, blocky particles in (A) are likely a redox-inert decomposition product of NNS. 


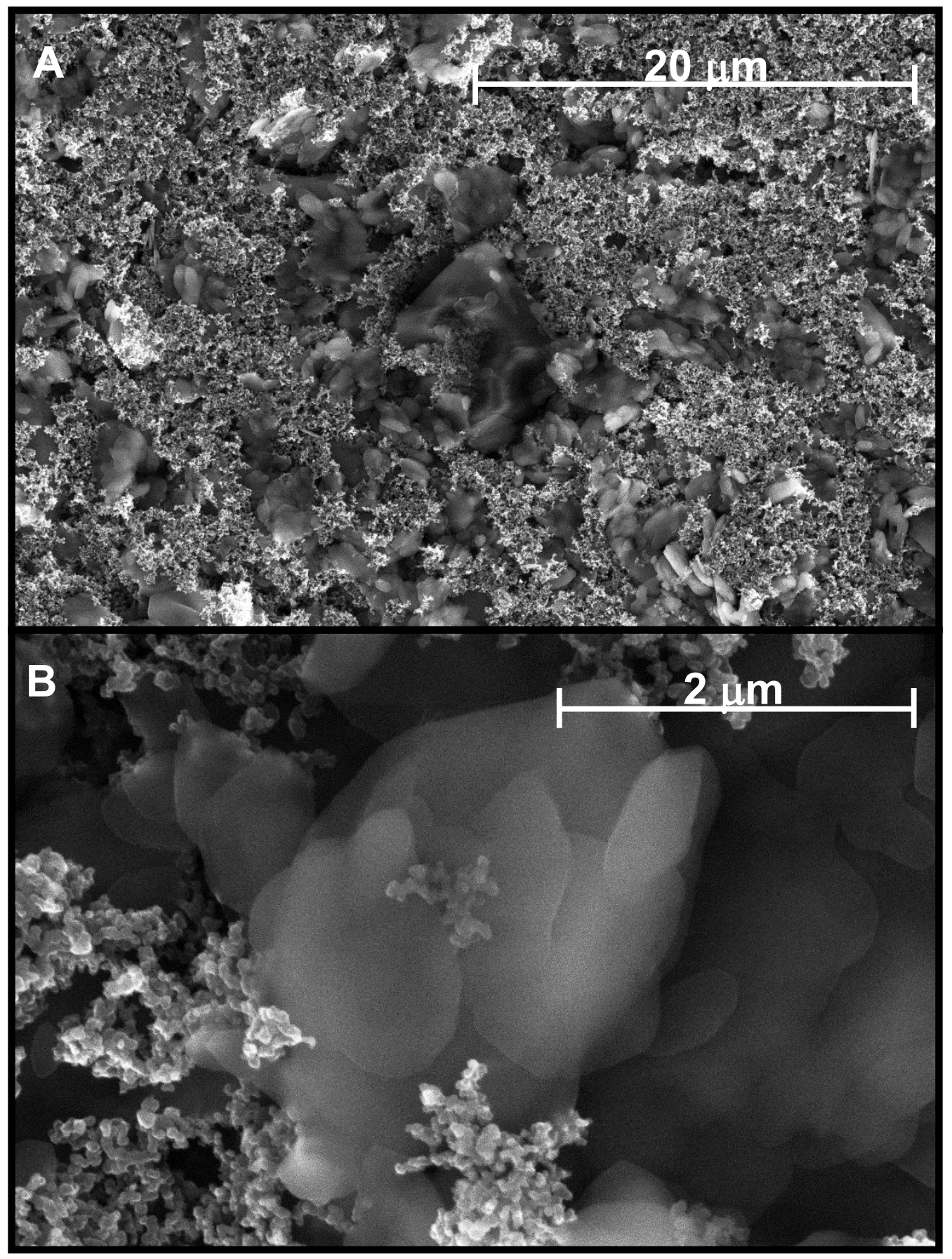

Figure S13. Micrographs of pristine NSN electrode showing (A) a wide-field view of the electrode surface with small, oval-shaped particles embedded in the conductive carbon additive, Super P, and (B) a single oval particle surrounded by the globular Super P. 


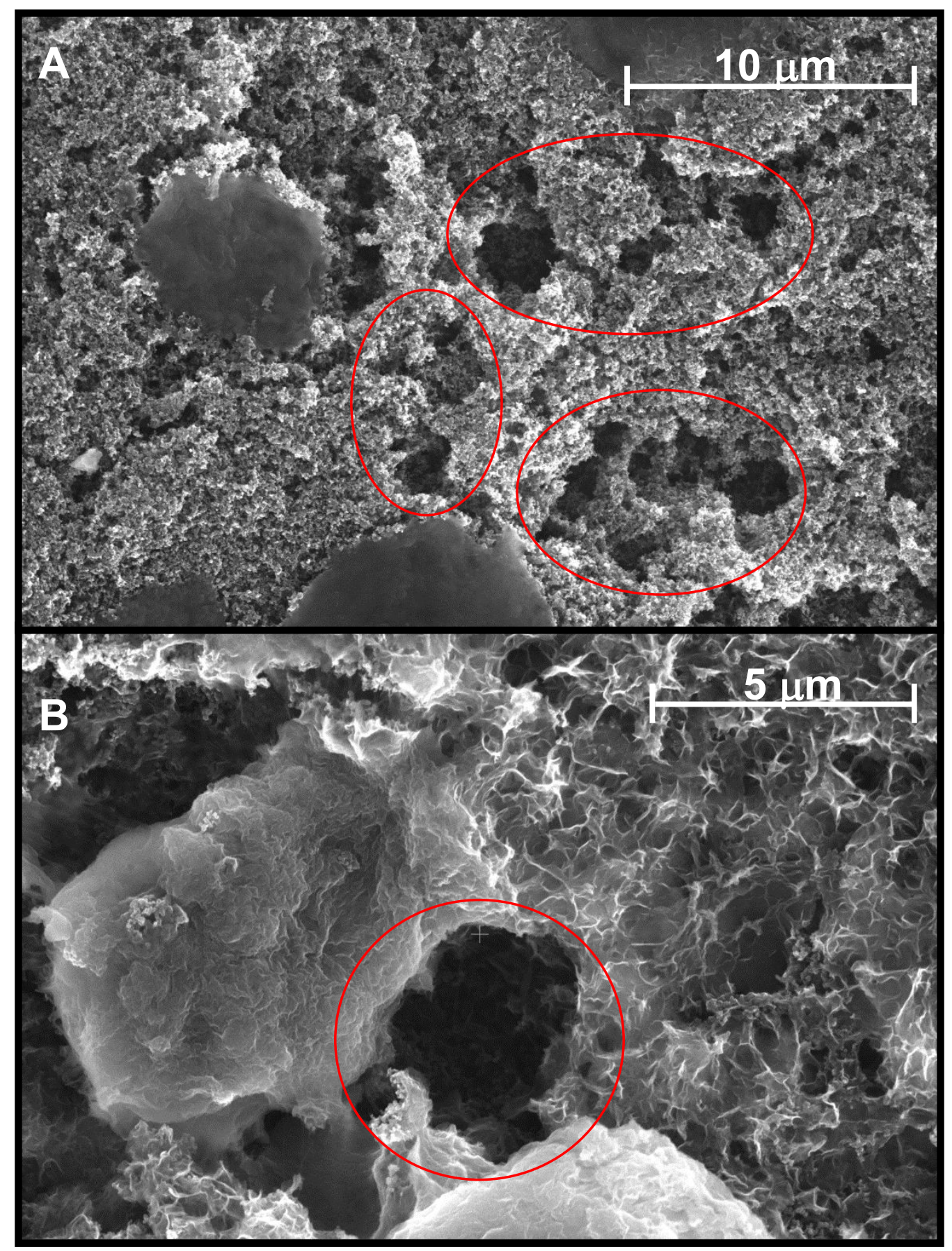

Figure S14. Micrographs of NSN electrode after two cycles showing (A) a midfield view of the electrode surface with a few large particles and red circles highlighting the pockets in the conductive carbon additive, Super P, where NSN particles once resided and (B) a severely eroded NSN particle with very rough surface morphology and a red circle highlighting the deep pocket in the Super P/NSN mixture. 


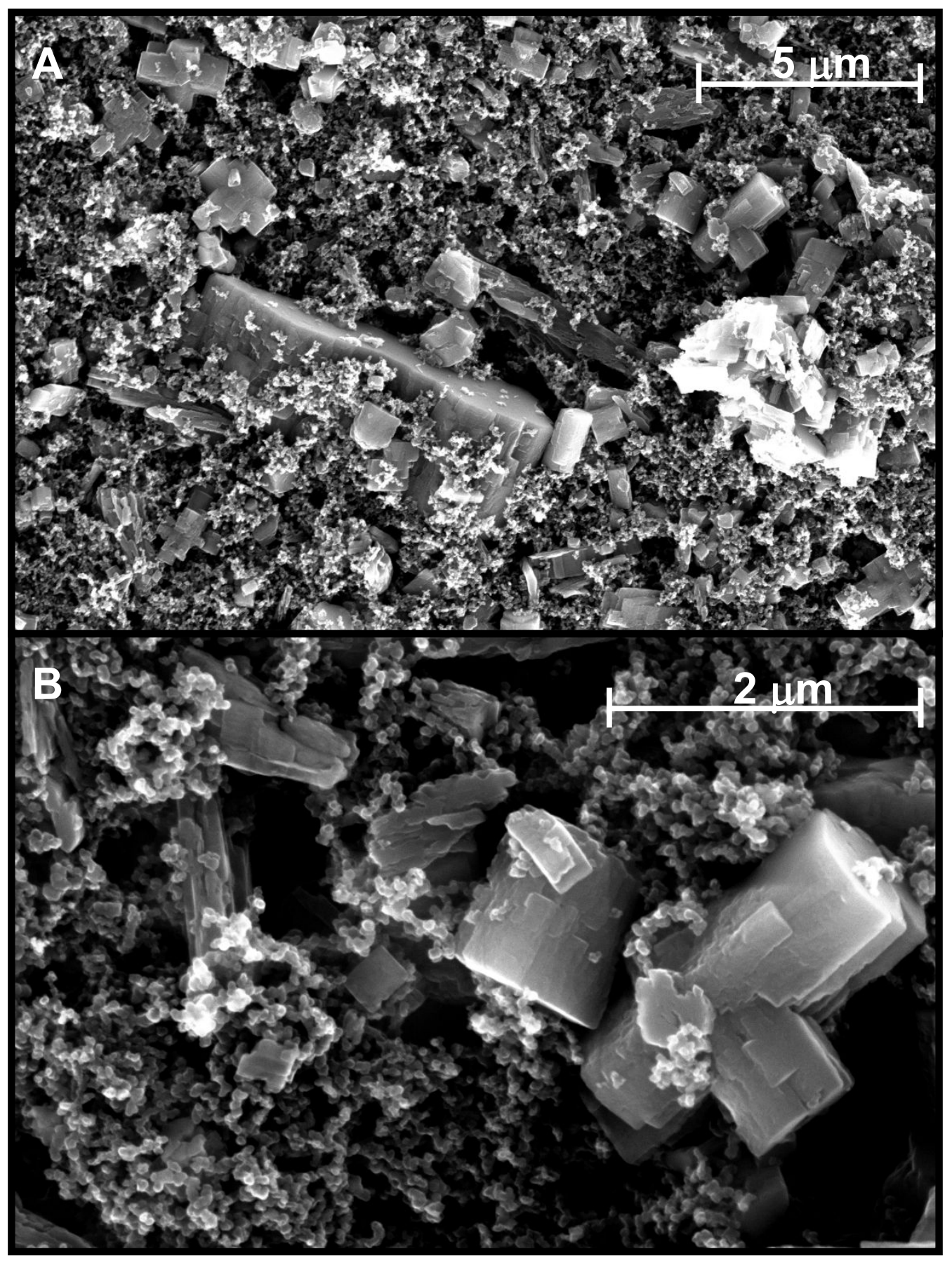

Figure S15. Micrographs of pristine NSS electrode showing (A) a midfield view of the electrode surface with several cross-shaped particles surrounded by the conductive carbon additive, Super P, and (B) a single crossshaped particle surrounded by smaller, broken particles and globular Super P. 


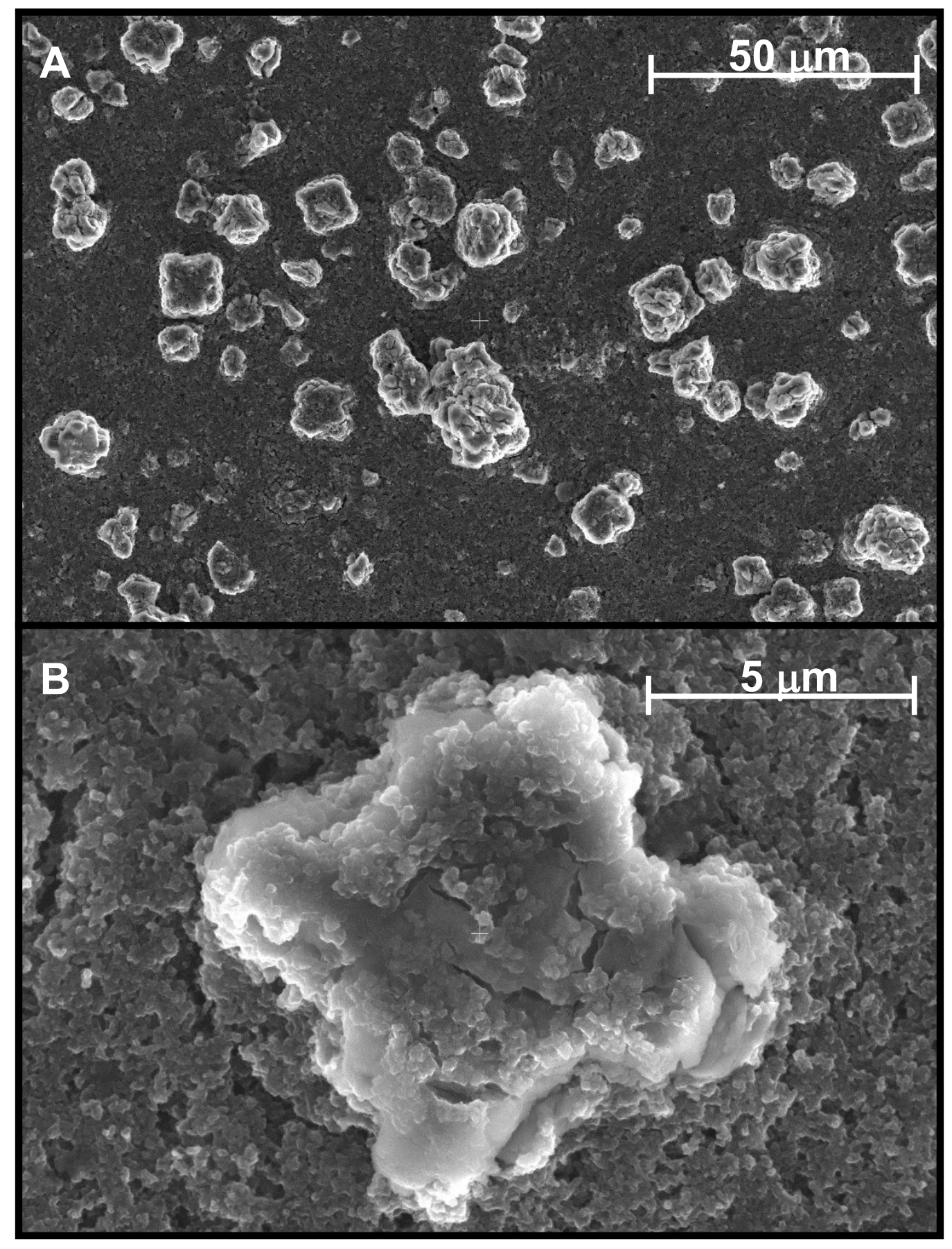

Figure S16. Micrographs of NSS electrode after 50 cycles showing (A) a wide-field view of the electrode surface with several cross-shaped and 'rosebud' particles surrounded by the conductive carbon additive, Super $\mathrm{P}$, and (B) a single cross-shaped particle with an amorphous morphology and clear surface cracks. 


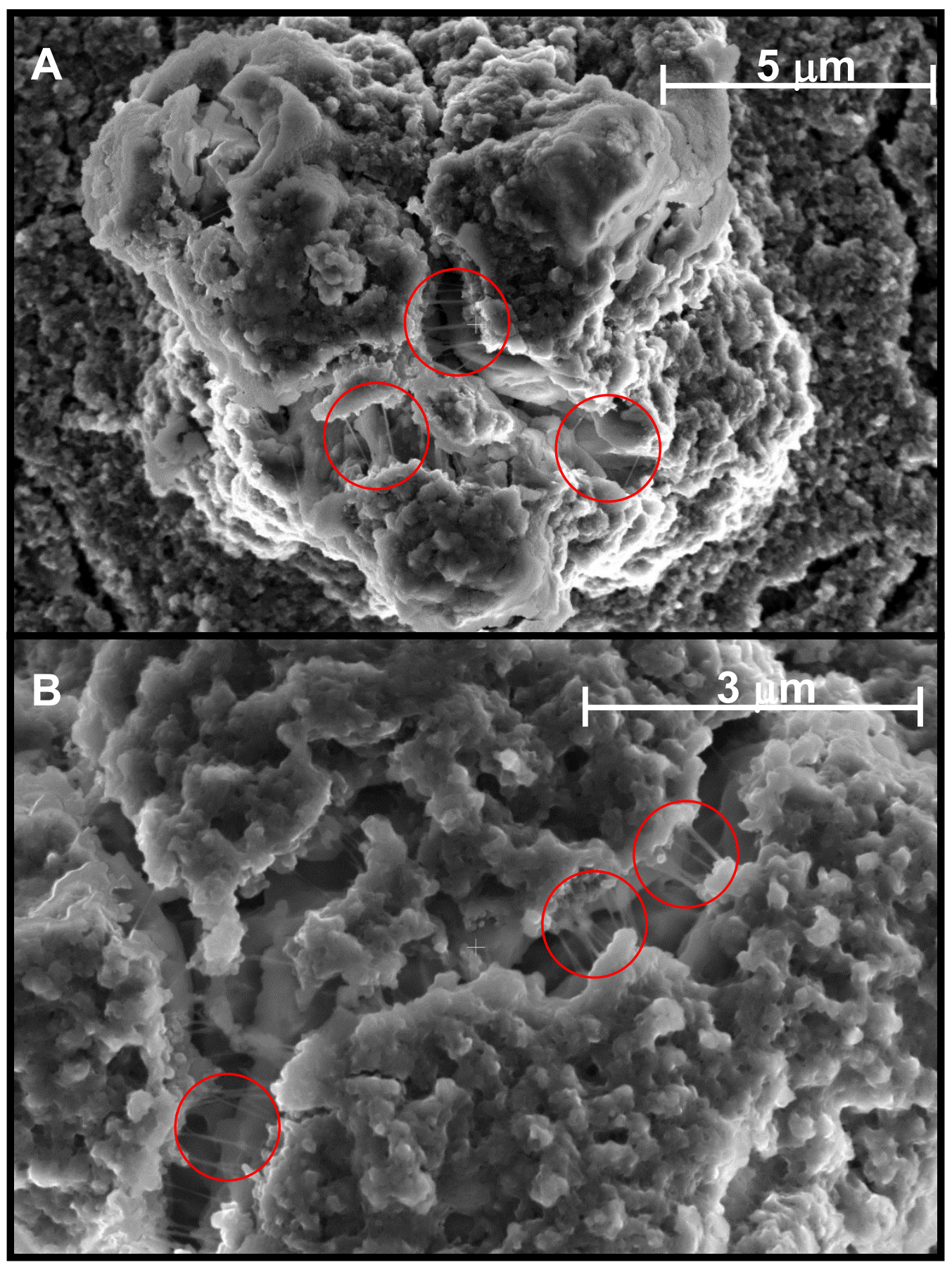

Figure S17. Micrographs of NSS particles after 50 cycles showing (A) the surface of a 'rosebud' particle with red circles highlighting the string-like attachments between cracks and (B) a close-up of the surface of a crossshaped particle with red circles highlighting the string-like attachments between cracks. 


\section{Solubility Study}

Solubility experiments were conducted in a glovebox with $500 \mu \mathrm{L}$ of $1 \mathrm{M} \mathrm{LiTFSI}$ and $0.2 \mathrm{M} \mathrm{LiNO}_{3}$ in 50:50 DME and DOL as the electrolyte. Dissolution control experiments were performed in dry DMF. Chemical reductants were chosen based on solution CV studies.

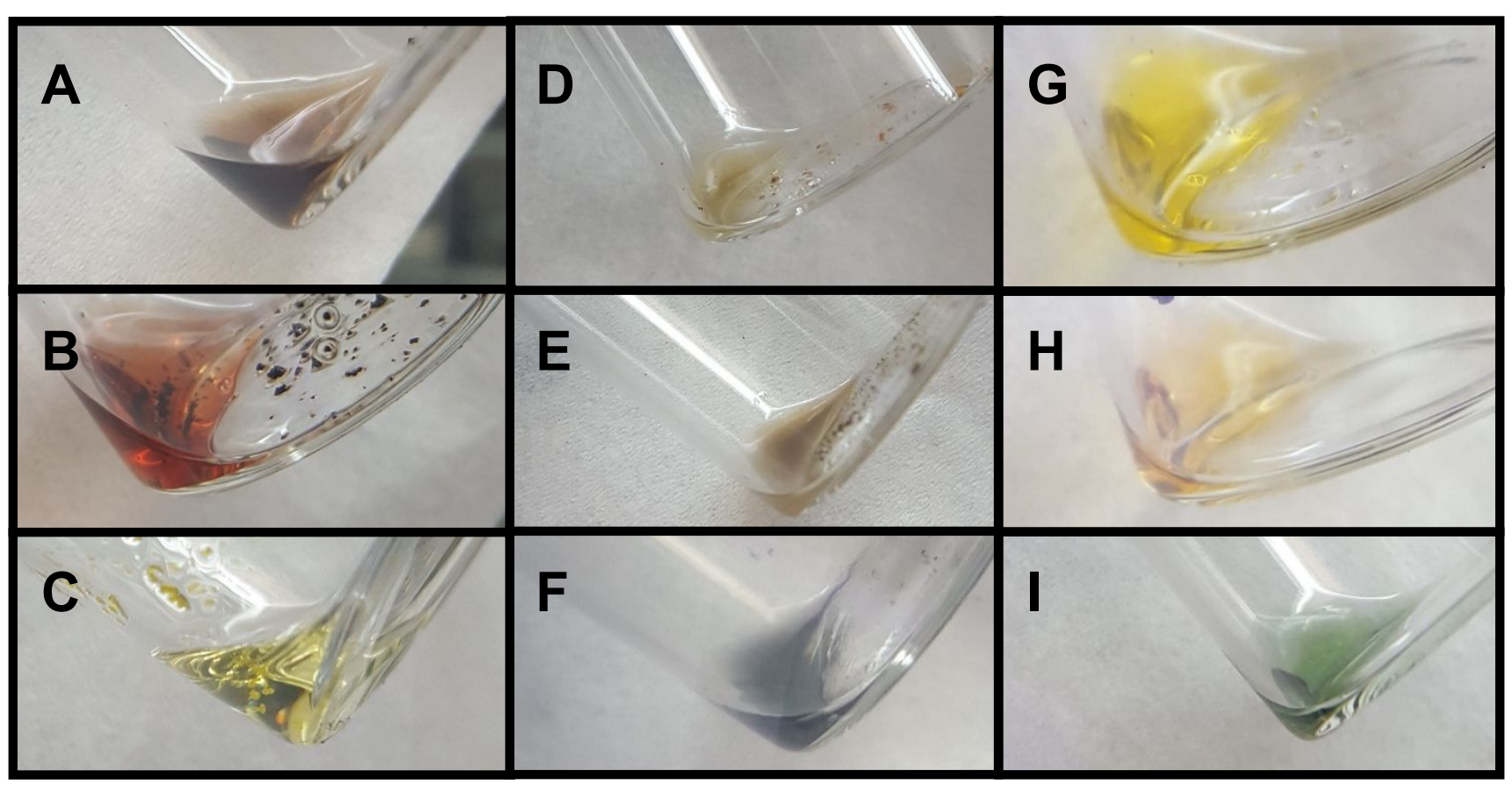

Figure S18. Pictures of (A) $\mathrm{CoCp}_{2}$ partially dissolved in electrolyte, (B) CoCp* ${ }_{2}$ partially dissolved in electrolyte, (C) FeCp* ${ }_{2}$ partially dissolved in electrolyte, (D) NNS suspended in electrolyte, (E) NSN suspended in electrolyte, (F) NSS suspended in electrolyte, (G) NNS dissolved in DMF, (H) NSN dissolved in DMF, and (I) NSS dissolved in DMF. 


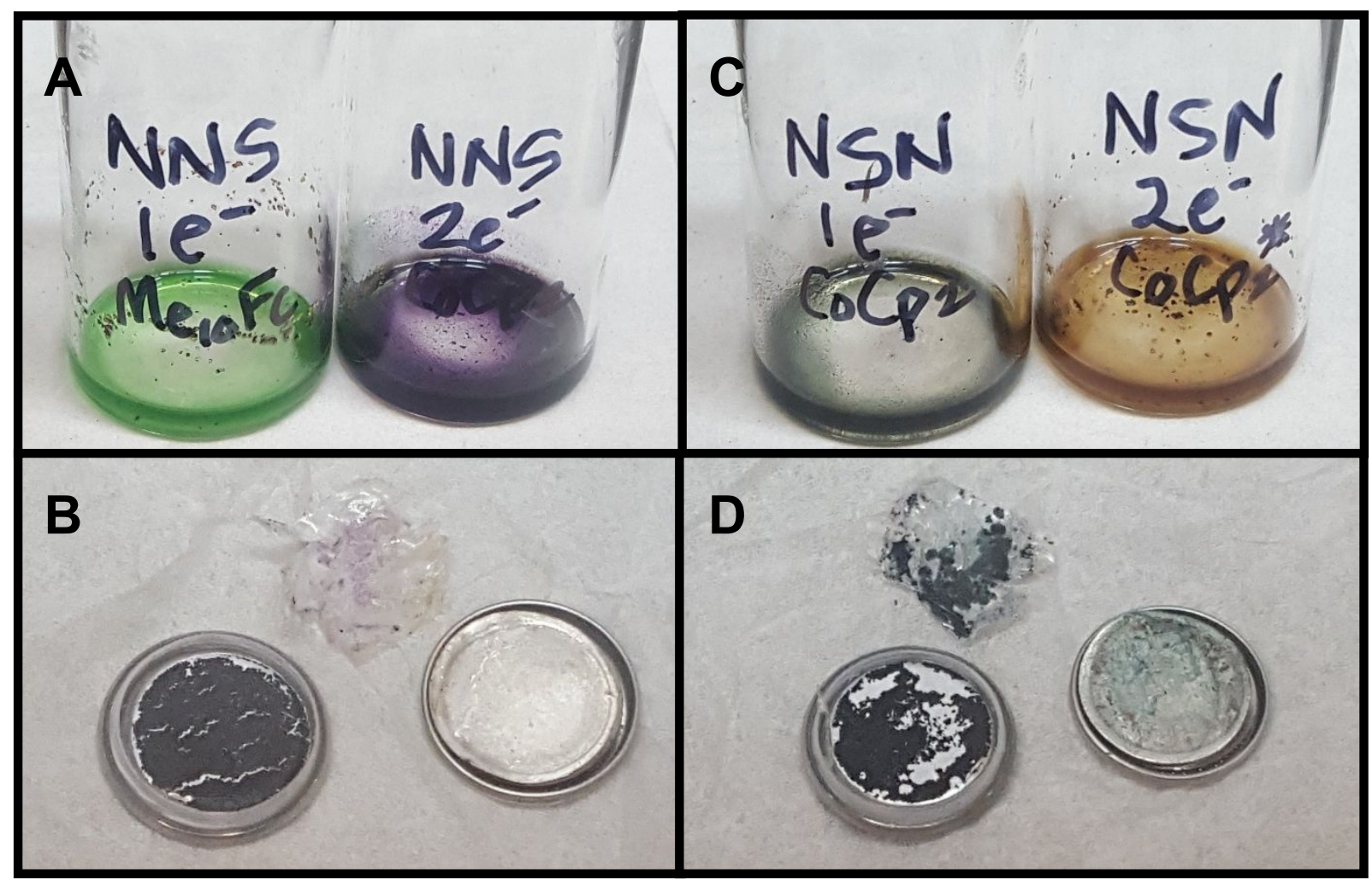

Figure S19. Pictures of (A) NNS after one-electron reduction with $\mathrm{FeCp}_{2}{ }_{2}$ (green, left) and two-electron reduction with $\mathrm{CoCp}_{2}$ (purple, right) in electrolyte, (B) disassembled NNS battery showing purple-coloured Celgard separator, (C) NSN after one-electron reduction with $\mathrm{CoCp}_{2}$ (blue-green, left) and two-electron reduction with $\mathrm{CoCp}_{2}^{*}$ (burnt orange, right) in electrolyte, and (D) disassembled NSN battery showing bluegreen colored Celgard separator and Li anode surface.

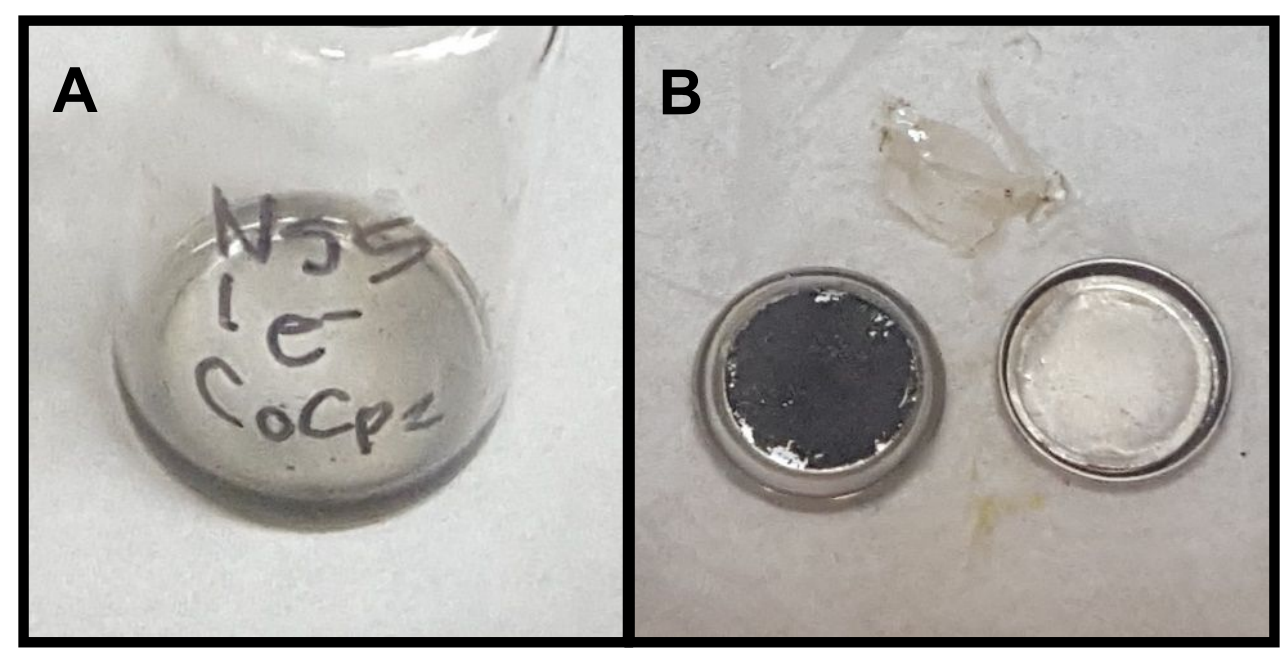

Figure S20. Pictures of (A) NSS after one-electron reduction with $\mathrm{CoCp}_{2}$ in electrolyte showing no color change of the mixture and (B) disassembled NSS battery after 50 cycles showing Celgard separator and Li anode surface in pristine condition. 


\section{Computational Details}

All computations were performed using Gaussian 09 software packages. ${ }^{9}$ Geometry optimizations for the unrestricted singlet ground states were carried out using density functional theory UB3LYP method ${ }^{10,11}$ with 6$311++\mathrm{G}(2 \mathrm{~d}, 2 \mathrm{p})$ basis set ${ }^{12,13}$ and GD3BJ dispersion correction. ${ }^{14}$ All geometry optimizations were performed using tight convergence thresholds for the energy $\left(10^{-6} E_{h}\right)$ and the maximum value of the energy nuclear gradient $\left(3 \times 10^{-4} \mathrm{E}_{\mathrm{h}} / \mathrm{a}_{0}\right)$. Harmonic vibrational frequency analyses were performed to confirm the converged structures are true stationary points on the potential energy surfaces, and no imaginary frequencies were obtained. The computational method was chosen based on the previous work by Cui et al., where they demonstrated the excellent performance of UB3LYP/6-311++G(2d,2p)/GD3BJ at predicting the strength of SOMO-SOMO interactions. ${ }^{15}$

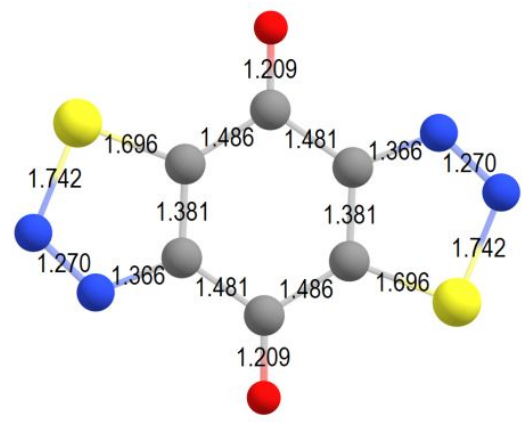

Neutral NNS

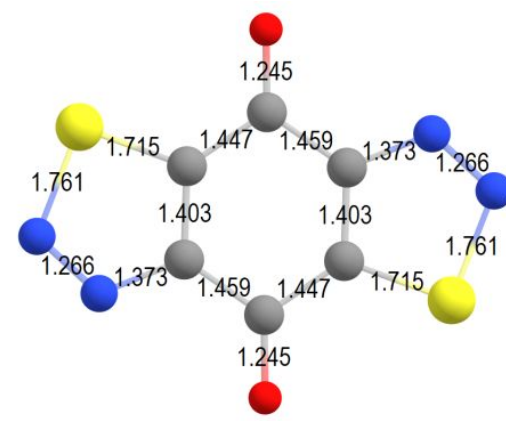

NNS Radical Anion

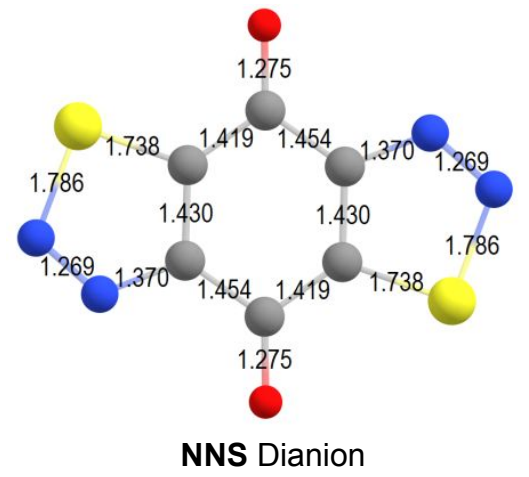

NNS Dianion

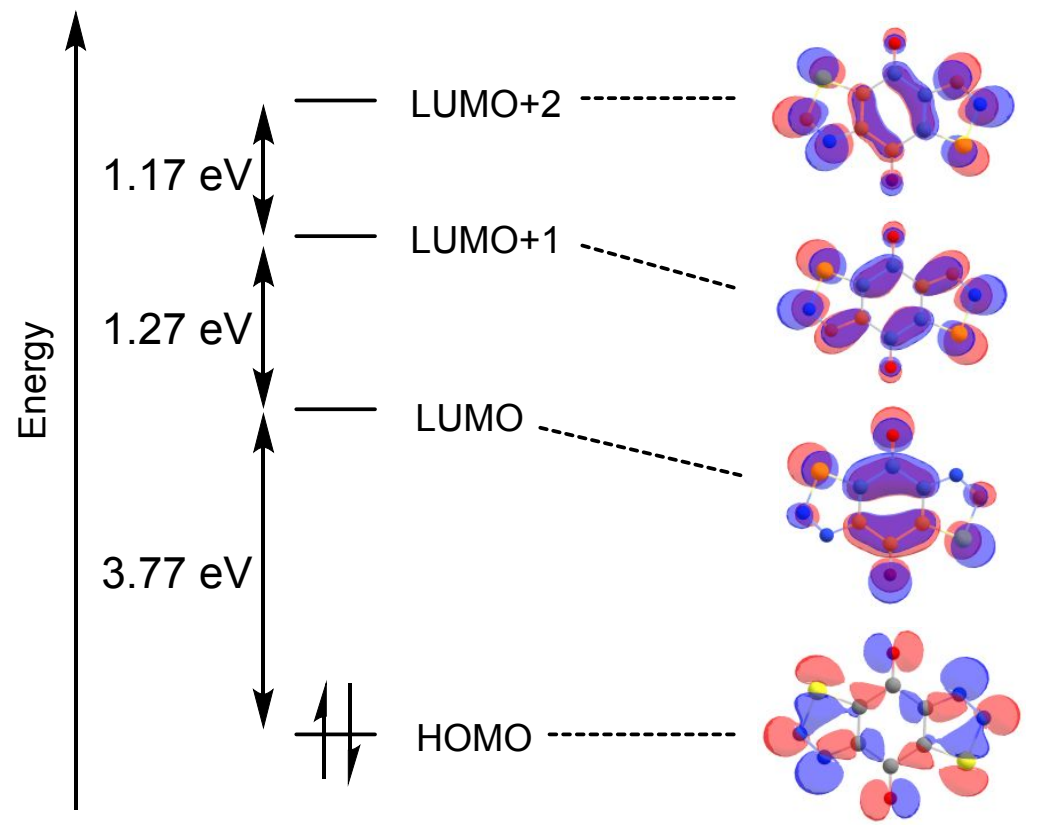

Figure S21. Calculated bond lengths in the neutral, radical anion, and dianion of NNS, along with a corresponding orbital energy diagram. 


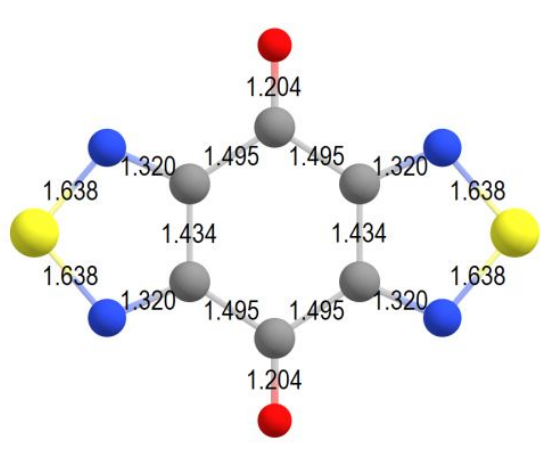

Neutral NSN

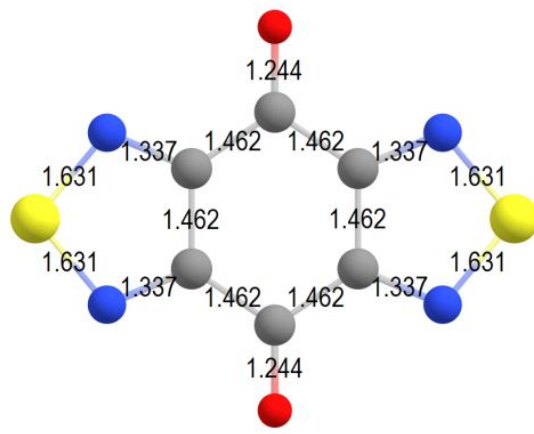

NSN Radical Anion

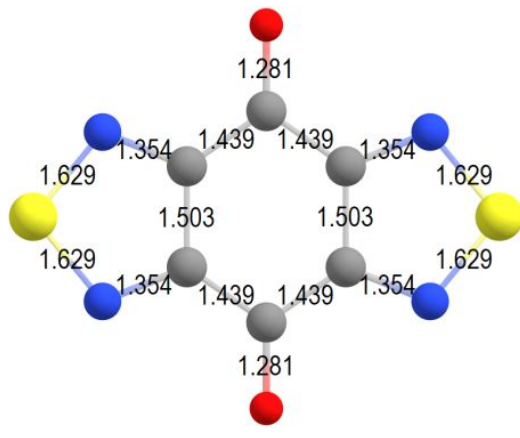

NSN Dianion

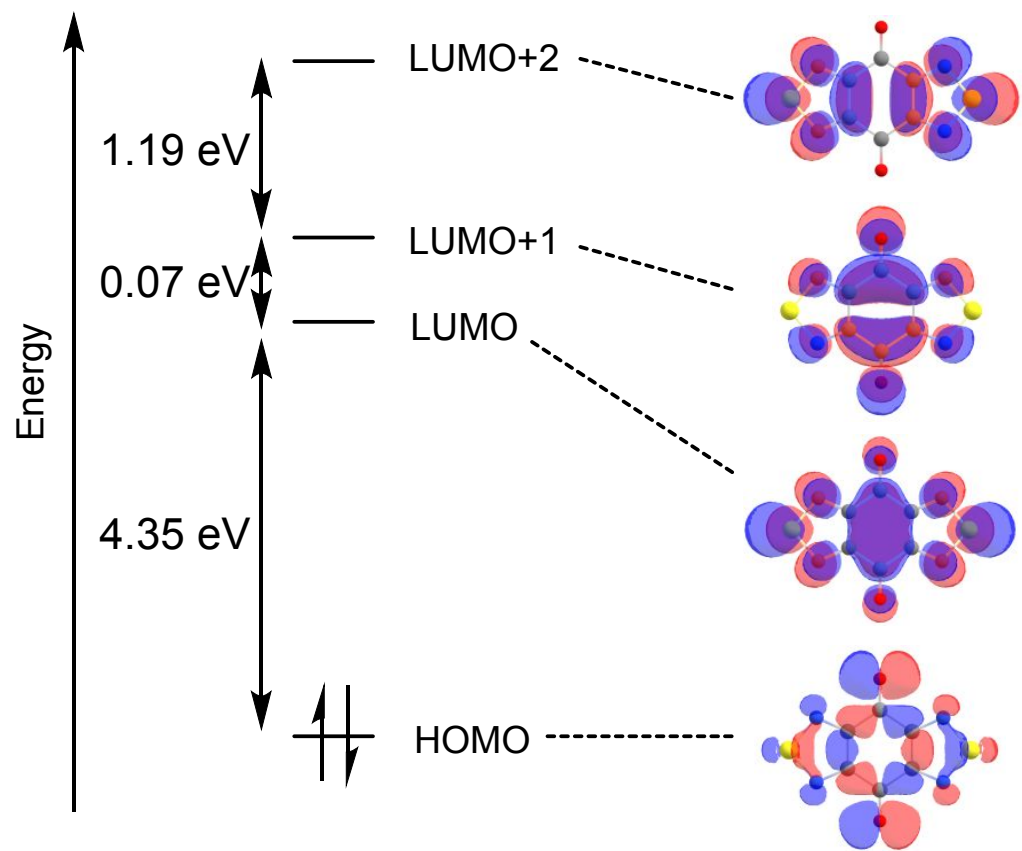

Figure S22. Calculated bond lengths in the neutral, radical anion, and dianion of NSN, along with a corresponding orbital energy diagram. 


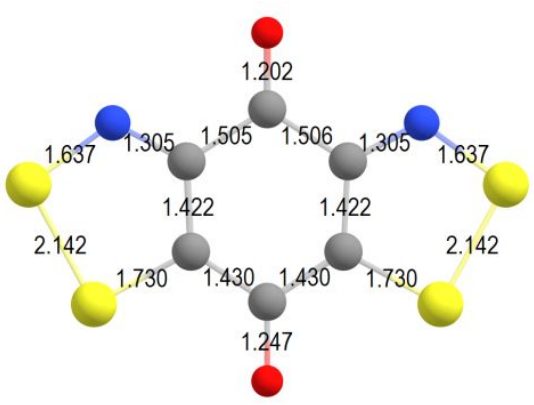

Neutral NSS

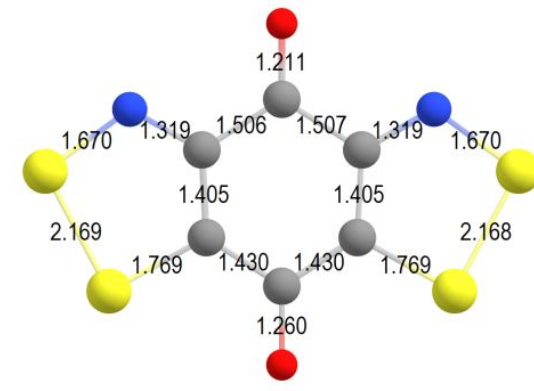

NSS Radical Anion

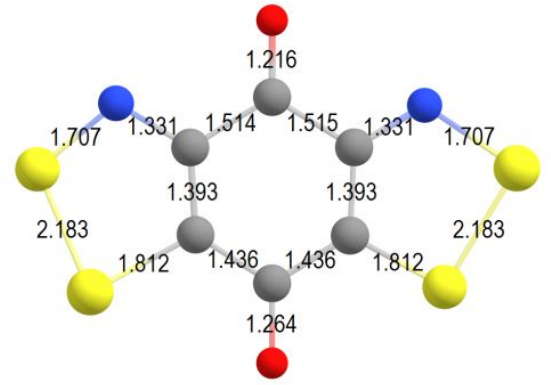

NSS Dianion

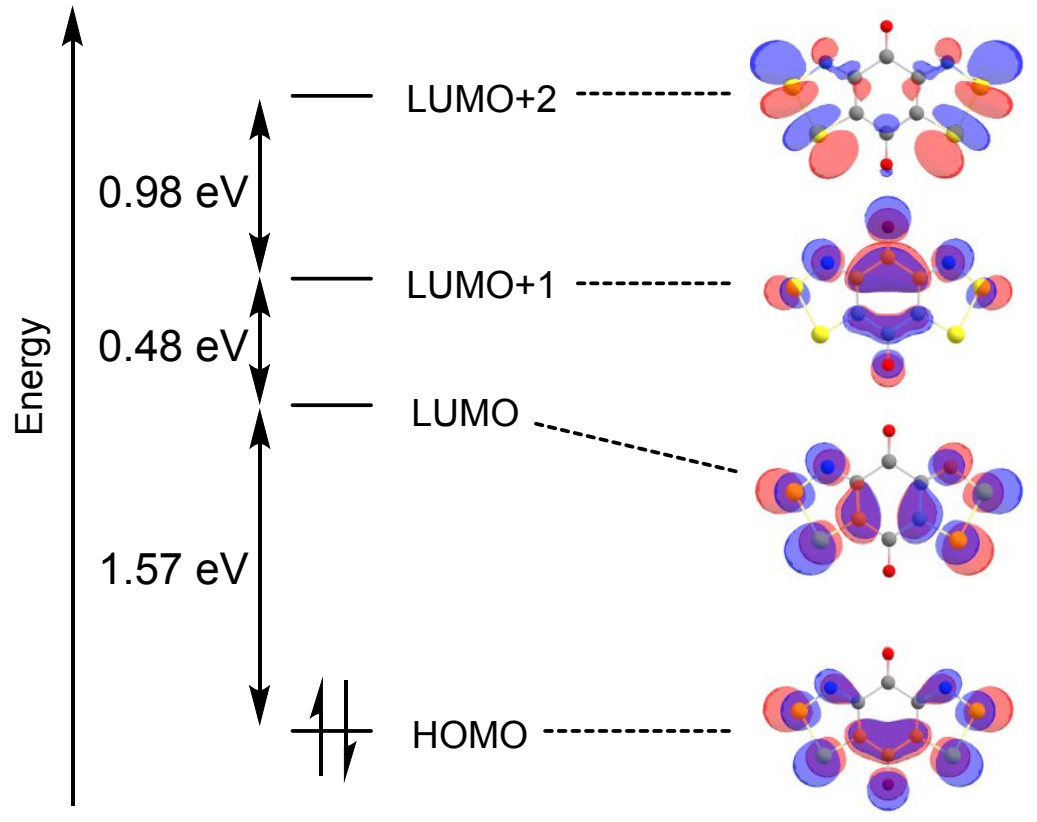

Figure S23. Calculated bond lengths in the neutral, radical anion, and dianion of NSS, along with a corresponding orbital energy diagram. 
The interaction energies $\left(\mathrm{E}_{\text {int }}\right)$ of all neutral and dianionic dimers of the thiazyl series were computed with reference to the energy of two monomers separated by $10 \AA\left(\mathrm{E}_{10 \AA}\right)$, at which point the intermolecular interaction energy is essentially negligible. For dianionic dimers, the intermolecular interaction energy between two thiazyl monomers can be written as the sum of an attractive SOMO-SOMO term and a repulsive van der Waals term ( $\mathrm{E}_{\mathrm{vdW}}$, including electrostatic repulsion, dispersion, and Pauli repulsion) based on the method described by Cui et al. ${ }^{15}$ :

$$
\mathrm{E}_{\text {int }}(\text { singlet })=\mathrm{E}_{\mathrm{SOMO}-\mathrm{SOMO}}+\mathrm{E}_{\mathrm{vdW}}
$$

Additionally, $\mathrm{E}_{\mathrm{vdW}}$ can be approximated by the interaction energy in the triplet state at the same geometry, in which case the SOMO-SOMO bond order becomes zero due to the equal occupancy of both bonding and antibonding orbitals:

$$
\mathrm{E}_{\mathrm{vdW}} \approx \mathrm{E}_{\text {int }} \text { (triplet) }
$$

Therefore, the SOMO-SOMO interaction energy ( $\mathrm{E}_{\text {SOMO-SOMO }}$ ) can be approximated based on the following equation:

$$
\mathrm{E}_{\mathrm{SOMO}-\mathrm{SOMO}}=\mathrm{E}_{\text {int }}(\text { singlet })-\mathrm{E}_{\text {int }}(\text { triplet })
$$
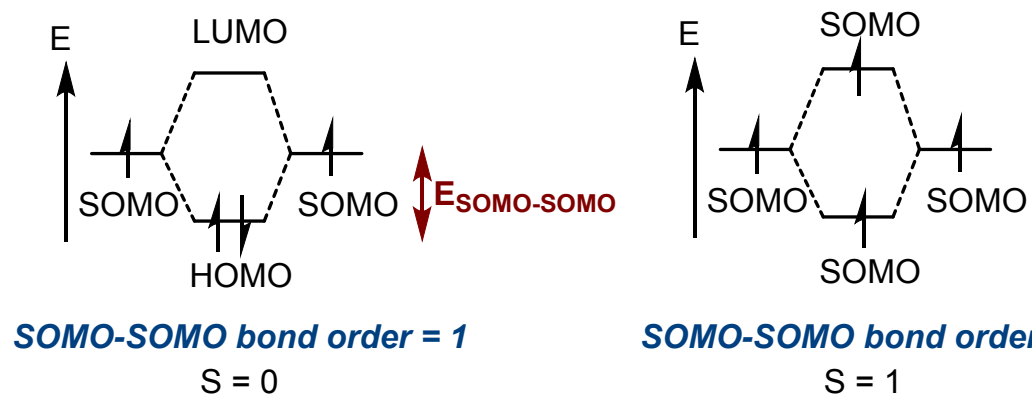

SOMO-SOMO bond order $=0$

$S=1$

To obtain molecular geometries for $\mathrm{E}_{\text {int }}$ calculations, we considered the binding energy of the thiazyl series in two configurations, namely $\pi$-stacking and thiazyl-stacking interactions, against $\mathrm{E}_{10 \AA}$. All the molecular geometries were converged to stationary points with no imaginary frequencies. The corresponding binding energies of each configuration are shown in Figure S24 and S25. The lowest energy configuration for $\mathbf{N S S}_{2}$ is $\pi$-stacking $\left(\mathrm{E}_{\text {int }}=-21.21 \mathrm{kcal} / \mathrm{mol}\right)$. For $\mathbf{N S N}_{2}$ and $\mathbf{N N S}_{2}$, the $\pi$-stacking and thiazyl-stacking configurations are energetically competitive $\left(\Delta \mathrm{E}_{\text {int }}<1 \mathrm{kcal} / \mathrm{mol}\right.$, Figure S24). At the dianionic state, all three thiazyls molecules have similar binding energy in both $\pi$-stacking and thiazyl-stacking configurations $\left(\Delta \mathrm{E}_{\text {int }}<5 \mathrm{kcal} / \mathrm{mol}\right)$, with $\mathbf{N S S}_{2}{ }^{2-}$ preferring thiazyl-stacking configuration slightly and $\mathbf{N S N}_{2}{ }^{2-}$ and $\mathbf{N N S}_{2}{ }^{2-}$ preferring $\pi$-stacking slightly (Figure S25). 


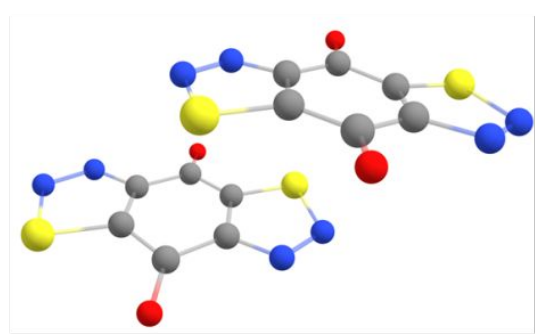

Neutral $\mathbf{N N S}_{2}$ thiazyl stacking $\mathrm{D}=3.39359 \AA$

$E_{\text {int }}=-13.09 \mathrm{kcal} / \mathrm{mol}$

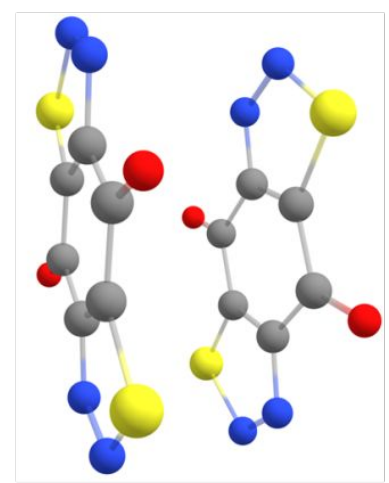

Neutral NNS $_{2} \pi$ stacking

$$
\mathrm{D}=3.40796 \AA
$$

$\mathrm{E}_{\text {int }}=-12.7 \mathrm{kcal} / \mathrm{mol}$

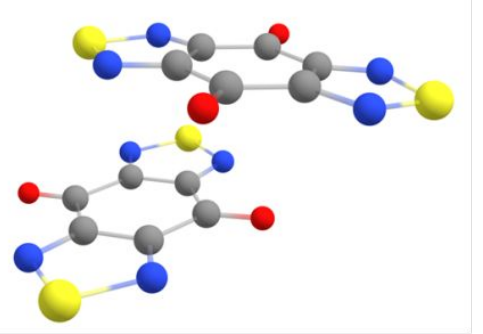

Neutral $\mathbf{N S N}_{2}$ thiazyl stacking $\mathrm{D}=3.37762 \AA$

$E_{\text {int }}=-13.41 \mathrm{kcal} / \mathrm{mol}$
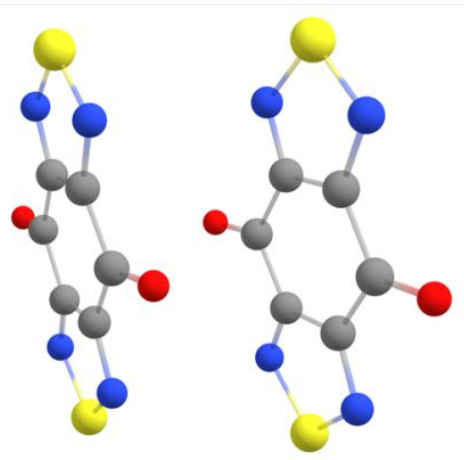

Neutral $\mathbf{N S N}_{2} \pi$ stacking

$$
\mathrm{D}=4.33599 \AA
$$

$E_{\text {int }}=-13.24 \mathrm{kcal} / \mathrm{mol}$

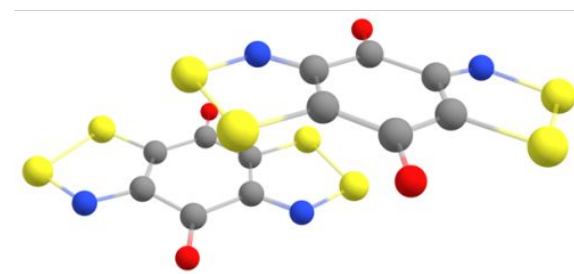

Neutral $\mathbf{N S S}_{2}$ thiazyl stacking $\mathrm{D}=3.62241 \AA$

$\mathrm{E}_{\text {int }}=-12.32 \mathrm{kcal} / \mathrm{mol}$

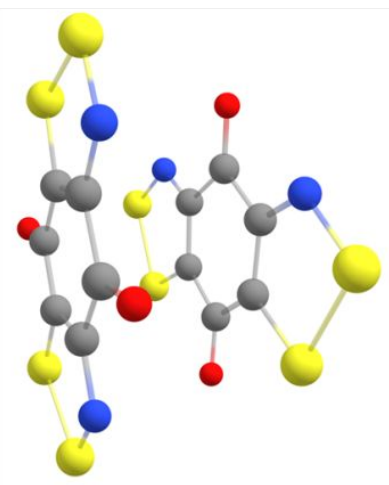

Neutral NSS $_{2} \pi$ stacking $\mathrm{D}=3.23274 \AA$

$E_{\text {int }}=-\mathbf{2 1 . 2 1 ~ k c a l} / \mathrm{mol}$

Figure S24. Interaction energies for $\mathbf{N N S}_{2}, \mathbf{N S N}_{2}$, and $\mathbf{N S S}_{2}$ at different stacking configurations; all $\mathrm{E}_{\text {int }}$ energies are referenced to $E_{10 \AA}$. D represents the closest distance between ring centers. 


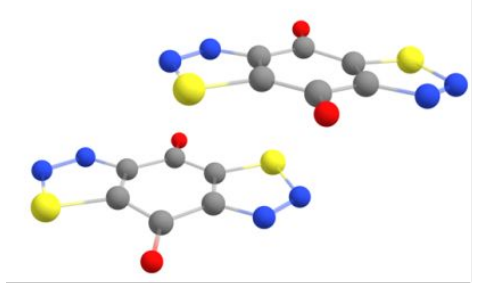

Dianion $\mathbf{N N S}_{2}{ }^{2-}$ thiazyl stacking $\mathrm{D}=3.39359 \AA$

$\mathrm{E}_{\text {int }}=8.93 \mathrm{kcal} / \mathrm{mol}$

$\mathrm{E}_{\text {sомо-sомо }}=-13.43 \mathrm{kcal} / \mathrm{mol}$

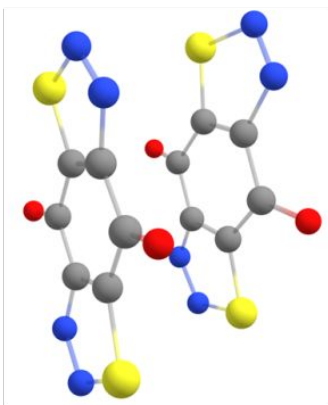

Dianion $\mathbf{N N S}_{2}{ }^{2-} \pi$ stacking

$$
D=3.21752 \AA
$$

$E_{\text {int }}=6.36 \mathrm{kcal} / \mathrm{mol}$

$\mathrm{E}_{\text {sомо-sомо }}=-3.11 \mathrm{kcal} / \mathrm{mol}$

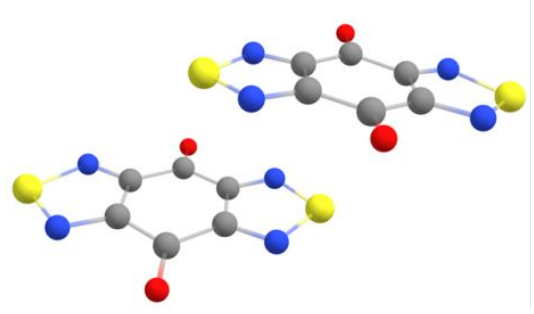

Dianion $\mathrm{NSN}_{2}{ }^{2-}$ thiazyl stacking $\mathrm{D}=3.28475 \AA$

$E_{\text {int }}=21.23 \mathrm{kcal} / \mathrm{mol}$

$\mathrm{E}_{\text {sомо-somo }}=-0.40 \mathrm{kcal} / \mathrm{mol}$
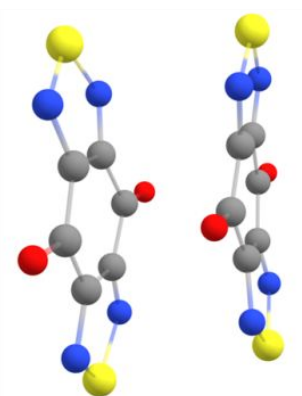

Dianion $\mathbf{N S N}_{2}{ }^{2-} \pi$ stacking $\mathrm{D}=3.47899 \AA$

$E_{\text {int }}=17.64 \mathrm{kcal} / \mathrm{mol}$

$\mathrm{E}_{\text {Sомо-somo }}=-9.42 \mathrm{kcal} / \mathrm{mol}$

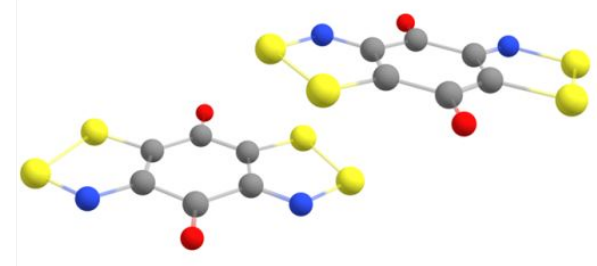

Dianion $\mathbf{N S S}_{2}{ }^{2-}$ thiazyl stacking $\mathrm{D}=3.19792 \AA$

$E_{\text {int }}=-0.35 \mathrm{kcal} / \mathrm{mol}$

$\mathrm{E}_{\text {sомо-somo }}=-24.07 \mathrm{kcal} / \mathrm{mol}$

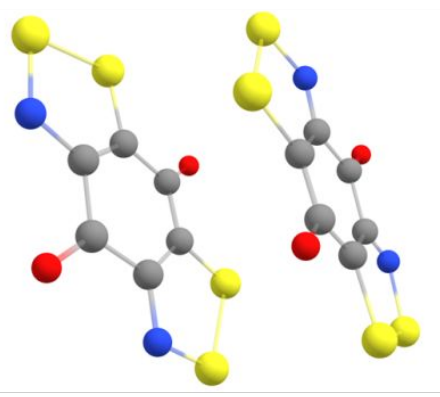

Dianion $\mathbf{N S S}_{2}{ }^{2-} \pi$ stacking

$\mathrm{D}=4.24110 \AA$

$E_{\text {int }}=3.34 \mathrm{kcal} / \mathrm{mol}$

$\mathrm{E}_{\text {sомо-somo }}=-21.37 \mathrm{kcal} / \mathrm{mol}$

Figure S25. Interaction and SOMO-SOMO energies for $\mathbf{N N S}_{2}{ }^{2-}, \mathbf{N S N}_{2}{ }^{2-}$, and $\mathbf{N S S}_{2}{ }^{2-}$ at different stacking configurations; all $\mathrm{E}_{\mathrm{int}}$ energies are referenced to $\mathrm{E}_{10 \AA}$. D represents the closest distance between ring centers. 


\begin{tabular}{|c|c|c|c|}
\hline \multicolumn{4}{|c|}{ Neutral NNS } \\
\hline \multicolumn{4}{|c|}{$E_{\text {singlet }}=-1394.6457618$ Hartree } \\
\hline 6 & 1.285020000 & -2.267429000 & 0.000366000 \\
\hline 6 & 3.364466000 & -0.856798000 & -0.000288000 \\
\hline 6 & 2.638869000 & 0.439938000 & -0.001089000 \\
\hline 6 & 0.559423000 & -0.970692000 & -0.000445000 \\
\hline 6 & 2.756246000 & -2.096242000 & 0.000415000 \\
\hline 6 & 1.167642000 & 0.268751000 & -0.001165000 \\
\hline 8 & 3.204968000 & 1.508378000 & -0.001664000 \\
\hline 8 & 0.718920000 & -3.335868000 & 0.000898000 \\
\hline 7 & 3.631692000 & -3.144847000 & 0.001048000 \\
\hline 7 & 0.292195000 & 1.317356000 & -0.001778000 \\
\hline 7 & -0.931704000 & 0.979204000 & -0.001300000 \\
\hline 7 & 4.855590000 & -2.806693000 & 0.000699000 \\
\hline 16 & -1.122200000 & -0.752596000 & -0.001270000 \\
\hline 16 & 5.046090000 & -1.074891000 & 0.000291000 \\
\hline
\end{tabular}

NNS Radical Anion

$E_{\text {singlet }}=-1394.7581533$ Hartree

$\begin{array}{lrrr}6 & 1.275908000 & -2.271408000 & -0.000217000 \\ 6 & 3.336282000 & -0.828910000 & -0.000467000 \\ 6 & 2.647980000 & 0.443918000 & -0.001687000 \\ 6 & 0.587606000 & -0.998581000 & -0.000661000 \\ 6 & 2.723675000 & -2.090598000 & 0.000172000 \\ 6 & 1.200213000 & 0.263108000 & -0.001281000 \\ 8 & 3.236377000 & 1.541005000 & -0.001462000 \\ 8 & 0.687511000 & -3.368496000 & 0.000583000 \\ 7 & 3.617979000 & -3.131972000 & 0.001208000 \\ 7 & 0.305910000 & 1.304483000 & -0.001531000 \\ 7 & -0.917258000 & 0.976064000 & -0.001378000 \\ 7 & 4.841147000 & -2.803553000 & 0.001551000 \\ 16 & -1.112714000 & -0.774520000 & -0.000293000 \\ 16 & 5.036601000 & -1.052970000 & 0.000182000\end{array}$

NNS Dianion

$E_{\text {singlet }}=-1394.6964407$ Hartree

$\begin{array}{lrrr}6 & 1.258530000 & -2.286596000 & 0.000614000 \\ 6 & 3.320764000 & -0.799075000 & -0.000148000 \\ 6 & 2.665358000 & 0.459107000 & -0.000573000 \\ 6 & 0.603124000 & -1.028414000 & -0.000333000 \\ 6 & 2.698543000 & -2.086737000 & 0.000413000 \\ 6 & 1.225345000 & 0.259247000 & -0.000900000 \\ 8 & 3.264898000 & 1.584841000 & -0.001452000 \\ 8 & 0.658991000 & -3.412331000 & 0.000705000 \\ 7 & 3.601048000 & -3.117939000 & 0.000771000 \\ 7 & 0.322840000 & 1.290449000 & -0.001822000 \\ 7 & -0.908151000 & 0.980655000 & -0.002254000 \\ & & & \mathrm{~S} 34\end{array}$


$-0.000588000$

\section{Neutral NSN}

$\mathrm{E}_{\text {singlet }}=-1394.6874541$ Hartree

$\begin{array}{lcrc}6 & 1.200070000 & -2.235028000 & 0.000499000 \\ 6 & 3.410529000 & -0.899390000 & -0.000288000 \\ 6 & 2.751484000 & 0.442065000 & -0.000950000 \\ 6 & 0.541026000 & -0.893573000 & -0.000579000 \\ 6 & 2.691664000 & -2.140021000 & 0.000324000 \\ 6 & 1.259889000 & 0.347059000 & -0.001189000 \\ 8 & 3.355579000 & 1.484004000 & -0.001325000 \\ 8 & 0.595975000 & -3.276966000 & 0.000687000 \\ 7 & 4.722503000 & -1.047108000 & 0.000153000 \\ 7 & 3.472357000 & -3.204788000 & 0.001123000 \\ 7 & -0.770949000 & -0.745856000 & -0.000830000 \\ 7 & 0.479197000 & 1.411825000 & -0.001805000 \\ 16 & -1.064371000 & 0.865263000 & -0.002156000 \\ 16 & 5.015925000 & -2.658228000 & 0.000180000\end{array}$

NSN Radical Anion $E_{\text {singlet }}=-1394.7706902$ Hartree

$\begin{array}{lcrc}6 & 1.197787000 & -2.238974000 & 0.000074000 \\ 6 & 3.389186000 & -0.870774000 & -0.000242000 \\ 6 & 2.753767000 & 0.446011000 & -0.001047000 \\ 6 & 0.562368000 & -0.922190000 & -0.000572000 \\ 6 & 2.656222000 & -2.135683000 & 0.000311000 \\ 6 & 1.295331000 & 0.342720000 & -0.001124000 \\ 8 & 3.377536000 & 1.521920000 & -0.001682000 \\ 8 & 0.574018000 & -3.314884000 & 0.000603000 \\ 7 & 4.716095000 & -1.036527000 & -0.000156000 \\ 7 & 3.459950000 & -3.204468000 & 0.000802000 \\ 7 & -0.764542000 & -0.756436000 & -0.000913000 \\ 7 & 0.491604000 & 1.411505000 & -0.001872000 \\ 16 & -1.039630000 & 0.850932000 & -0.001488000 \\ 16 & 4.991184000 & -2.643895000 & 0.001149000\end{array}$

NSN Dianion

$E_{\text {singlet }}=-1394.6788222$ Hartree

$\begin{array}{llrr}6 & 1.186677000 & -2.258154000 & 0.000341000 \\ 6 & 3.374672000 & -0.838754000 & -0.000231000 \\ 6 & 2.764877000 & 0.465191000 & -0.000903000 \\ 6 & 0.576882000 & -0.954210000 & -0.000500000 \\ 6 & 2.621214000 & -2.138937000 & 0.000359000 \\ 6 & 1.330339000 & 0.345974000 & -0.001090000 \\ 8 & 3.407335000 & 1.573467000 & -0.001615000 \\ 8 & 0.544219000 & -3.366430000 & 0.000618000 \\ 7 & 4.715503000 & -1.026633000 & -0.000149000\end{array}$


0.000772000

\section{Neutral NSS}

$E_{\text {singlet }}=-2081.5858342$ Hartree

$\begin{array}{lrrr}16 & -4.933725000 & 4.402859000 & -6.766176000 \\ 6 & -6.483190000 & 6.374243000 & -10.582911000 \\ 6 & -5.989936000 & 7.129988000 & -9.484493000 \\ 6 & -6.507505000 & 4.870385000 & -10.516966000 \\ 6 & -5.485956000 & 6.603311000 & -8.253708000 \\ 6 & -5.979696000 & 4.304542000 & -9.225518000 \\ 6 & -5.514703000 & 5.174102000 & -8.201553000 \\ 7 & -5.953491000 & 3.011247000 & -9.056007000 \\ 16 & -5.363511000 & 2.486569000 & -7.621437000 \\ 7 & -6.918902000 & 6.975609000 & -11.655538000 \\ 16 & -6.855881000 & 8.611701000 & -11.637966000 \\ 16 & -6.013894000 & 8.848303000 & -9.682348000 \\ 8 & -6.912512000 & 4.182312000 & -11.415836000 \\ 8 & -5.064956000 & 7.317129000 & -7.321337000\end{array}$

NSS Radical Anion

\section{$E_{\text {singlet }}=-2081.6832824$ Hartree}

$\begin{array}{lrrr}16 & -4.918109000 & 4.386798000 & -6.728872000 \\ 6 & -6.480867000 & 6.388331000 & -10.578046000 \\ 6 & -5.992751000 & 7.133679000 & -9.491344000 \\ 6 & -6.500015000 & 4.884108000 & -10.498923000 \\ 6 & -5.491668000 & 6.593978000 & -8.265699000 \\ 6 & -5.974078000 & 4.304769000 & -9.211522000 \\ 6 & -5.514792000 & 5.165851000 & -8.200567000 \\ 7 & -5.963852000 & 2.992894000 & -9.078734000 \\ 16 & -5.361468000 & 2.458383000 & -7.615373000 \\ 7 & -6.929662000 & 6.958659000 & -11.679046000 \\ 16 & -6.864689000 & 8.627250000 & -11.660695000 \\ 16 & -6.012577000 & 8.891747000 & -9.684176000 \\ 8 & -6.906834000 & 4.191130000 & -11.404598000 \\ 8 & -5.066498000 & 7.314721000 & -7.324200000\end{array}$

NSS Dianion

$E_{\text {singlet }}=-2081.6185284$ Hartree

$\begin{array}{lllr}16 & -5.092502000 & 4.365287000 & -6.629561000 \\ 6 & -6.490853000 & 6.408987000 & -10.575088000 \\ 6 & -6.062455000 & 7.145570000 & -9.472506000 \\ 6 & -6.490005000 & 4.897316000 & -10.482578000 \\ 6 & -5.495870000 & 6.585082000 & -8.277642000 \\ 6 & -5.956318000 & 4.296398000 & -9.198729000 \\ 6 & -5.445081000 & 5.150717000 & -8.223849000\end{array}$




$\begin{array}{lrrr}7 & -6.050967000 & 2.976474000 & -9.059068000 \\ 16 & -5.202799000 & 2.451432000 & -7.673857000 \\ 7 & -6.861811000 & 6.947794000 & -11.733989000 \\ 16 & -7.025281000 & 8.640780000 & -11.589611000 \\ 16 & -5.837573000 & 8.917138000 & -9.779374000 \\ 8 & -6.896906000 & 4.201262000 & -11.392783000 \\ 8 & -5.069439000 & 7.308062000 & -7.333163000\end{array}$

Cartesian coordinates of thiazyl dimers optimized at UB3LYP/6-311++G(2d,2p)/GD3BJ level $\mathbf{N N S}_{2} 10 \AA$,

$\begin{array}{lrrr}\mathrm{E}_{\text {singlet }}=-2789.29166181 & \text { Hartree } & \\ 6 & -2.612034000 & 0.069829000 & -0.633240000 \\ 6 & -0.656197000 & 1.603695000 & -0.263698000 \\ 6 & -1.469298000 & 2.847400000 & -0.256927000 \\ 6 & -3.425117000 & 1.313509000 & -0.626587000 \\ 6 & -1.167986000 & 0.332834000 & -0.434564000 \\ 6 & -2.913360000 & 2.584353000 & -0.455651000 \\ 8 & -0.987112000 & 3.945695000 & -0.104515000 \\ 8 & -3.094286000 & -1.028510000 & -0.785481000 \\ 7 & -0.224841000 & -0.654750000 & -0.403978000 \\ 7 & -3.856560000 & 3.571938000 & -0.486259000 \\ 7 & -5.043520000 & 3.158740000 & -0.666264000 \\ 7 & 0.962188000 & -0.241363000 & -0.224029000 \\ 16 & -5.105819000 & 1.424368000 & -0.822105000 \\ 16 & 1.024502000 & 1.492739000 & -0.068281000 \\ 6 & 14.405432000 & -2.051201000 & -0.285329000 \\ 6 & 12.565211000 & -3.762426000 & -0.283947000 \\ 6 & 13.480108000 & -4.933133000 & -0.266961000 \\ 6 & 15.320320000 & -3.221866000 & -0.268449000 \\ 6 & 12.977457000 & -2.444808000 & -0.292383000 \\ 6 & 14.908090000 & -4.539489000 & -0.259963000 \\ 8 & 13.083802000 & -6.075429000 & -0.259784000 \\ 8 & 14.801727000 & -0.908857000 & -0.292405000 \\ 7 & 11.952641000 & -1.541884000 & -0.307910000 \\ 7 & 15.932919000 & -5.442414000 & -0.244572000 \\ 7 & 17.090991000 & -4.921845000 & -0.240651000 \\ 7 & 10.794548000 & -2.062616000 & -0.311959000 \\ 16 & 17.015615000 & -3.181414000 & -0.256444000 \\ 16 & 10.869928000 & -3.802842000 & -0.296205000\end{array}$

$\mathbf{N N S}_{2} \pi$-stacking

$\mathrm{E}_{\text {singlet }}=-2789.31190550$ Hartree

$\begin{array}{llll}6 & 6.341548000 & -4.528575000 & 2.635832000 \\ 6 & 7.502177000 & -2.308999000 & 2.875535000 \\ 6 & 6.246370000 & -1.523571000 & 2.980554000 \\ 6 & 5.086344000 & -3.741558000 & 2.719368000 \\ & & & S 37\end{array}$




$\begin{array}{llll}6 & 7.553088000 & -3.680760000 & 2.722216000 \\ 6 & 5.035145000 & -2.369823000 & 2.885043000 \\ 8 & 6.233515000 & -0.320257000 & 3.104255000 \\ 8 & 6.363032000 & -5.728843000 & 2.488352000 \\ 7 & 8.819623000 & -4.181478000 & 2.623969000 \\ 7 & 3.767804000 & -1.863371000 & 2.919159000 \\ 7 & 2.852313000 & -2.736306000 & 2.788589000 \\ 7 & 9.735915000 & -3.301168000 & 2.688390000 \\ 16 & 3.503904000 & -4.333196000 & 2.594381000 \\ 16 & 9.086651000 & -1.704015000 & 2.880717000 \\ 6 & 5.932754000 & -4.154274000 & -0.647757000 \\ 6 & 6.122575000 & -1.651566000 & -0.470636000 \\ 6 & 7.607122000 & -1.637804000 & -0.500470000 \\ 6 & 7.416473000 & -4.141895000 & -0.656601000 \\ 6 & 5.352128000 & -2.795750000 & -0.539170000 \\ 6 & 8.188111000 & -2.995888000 & -0.599459000 \\ 8 & 8.255105000 & -0.619101000 & -0.422462000 \\ 8 & 5.277628000 & -5.169546000 & -0.699912000 \\ 7 & 4.008244000 & -2.564738000 & -0.466356000 \\ 7 & 9.532535000 & -3.232765000 & -0.604625000 \\ 7 & 9.845975000 & -4.464196000 & -0.655920000 \\ 7 & 3.694582000 & -1.337692000 & -0.346181000 \\ 16 & 8.444962000 & -5.487321000 & -0.695597000 \\ 16 & 5.094149000 & -0.312894000 & -0.306201000\end{array}$

$\mathbf{N N S}_{2}$ thiazyl-stacking

$\mathrm{E}_{\text {singlet }}=-2789.31252790$ Hartree

$\begin{array}{lrrr}6 & 6.394708000 & -4.003781000 & 1.609592000 \\ 6 & 8.461134000 & -3.167479000 & 2.772492000 \\ 6 & 7.936370000 & -1.791121000 & 2.981068000 \\ 6 & 5.884530000 & -2.625887000 & 1.790584000 \\ 6 & 7.771183000 & -4.175955000 & 2.132419000 \\ 6 & 6.577814000 & -1.611729000 & 2.424745000 \\ 8 & 8.581600000 & -0.927725000 & 3.529135000 \\ 8 & 5.758231000 & -4.890008000 & 1.085048000 \\ 7 & 8.475533000 & -5.339389000 & 2.007051000 \\ 7 & 5.908704000 & -0.423377000 & 2.462776000 \\ 7 & 4.767775000 & -0.447543000 & 1.903860000 \\ 7 & 9.644774000 & -5.301006000 & 2.506588000 \\ 16 & 4.401728000 & -2.014174000 & 1.246425000 \\ 16 & 9.992118000 & -3.751391000 & 3.214526000 \\ 6 & 8.587766000 & -2.170201000 & -0.550642000 \\ 6 & 8.291401000 & -4.532753000 & -1.348352000 \\ 6 & 9.686532000 & -4.946207000 & -1.039626000 \\ 6 & 9.984563000 & -2.572913000 & -0.258755000 \\ 6 & 7.792421000 & -3.258373000 & -1.154566000 \\ 6 & 10.490712000 & -3.841516000 & -0.460273000 \\ 8 & 10.107783000 & -6.055713000 & -1.259438000 \\ 8 & 8.147573000 & -1.076497000 & -0.271093000 \\ & & & S 38\end{array}$




$\begin{array}{lrrr}7 & 6.485482000 & -3.110520000 & -1.523219000 \\ 7 & 11.796416000 & -3.981135000 & -0.083278000 \\ 7 & 12.323713000 & -2.925632000 & 0.386122000 \\ 7 & 5.948222000 & -4.170272000 & -1.976208000 \\ 16 & 11.198989000 & -1.594358000 & 0.408831000 \\ 16 & 7.058223000 & -5.504878000 & -1.978457000\end{array}$

$\mathbf{N N S}_{2}{ }^{2-} 10 \AA$

$\mathrm{E}_{\text {singlet }}=-2789.45540158$ Hartree

$E_{\text {triplet }}=-2789.48444475$ Hartree

$\begin{array}{lrrr}6 & 0.505445000 & -9.069077000 & -3.264240000 \\ 6 & 2.230468000 & -9.288917000 & -1.438430000 \\ 6 & 1.813797000 & -10.596263000 & -0.972085000 \\ 6 & 0.089412000 & -10.374708000 & -2.797773000 \\ 6 & 1.642265000 & -8.570078000 & -2.490341000 \\ 6 & 0.676572000 & -11.095333000 & -1.745776000 \\ 8 & 2.362226000 & -11.200595000 & -0.035547000 \\ 8 & -0.045858000 & -8.468256000 & -4.202288000 \\ 7 & 2.236906000 & -7.356328000 & -2.720832000 \\ 7 & 0.081918000 & -12.307749000 & -1.515728000 \\ 7 & -0.893786000 & -12.594944000 & -2.273585000 \\ 7 & 3.211805000 & -7.069477000 & -1.962930000 \\ 16 & -1.203573000 & -11.305493000 & -3.435069000 \\ 16 & 3.521978000 & -8.357177000 & -0.802419000 \\ 6 & 12.824630000 & 2.185877000 & 0.205274000 \\ 6 & 10.351102000 & 2.523653000 & 0.559019000 \\ 6 & 10.430859000 & 3.907427000 & 0.982122000 \\ 6 & 12.903678000 & 3.568161000 & 0.627543000 \\ 6 & 11.439527000 & 1.714940000 & 0.197877000 \\ 6 & 11.816084000 & 4.378726000 & 0.989136000 \\ 8 & 9.441401000 & 4.590253000 & 1.294819000 \\ 8 & 13.817513000 & 1.506152000 & -0.106218000 \\ 7 & 11.077672000 & 0.442437000 & -0.162208000 \\ 7 & 12.178071000 & 5.650175000 & 1.348077000 \\ 7 & 13.420166000 & 5.902800000 & 1.301418000 \\ 7 & 9.836092000 & 0.190549000 & -0.116079000 \\ 16 & 14.340189000 & 4.495542000 & 0.771130000 \\ 16 & 8.916362000 & 1.595764000 & 0.414042000 \\ 6 & & & \end{array}$

$\mathbf{N N S}_{2}{ }^{2-} \pi$-stacking

$E_{\text {singlet }}=-2789.44528911$ Hartree

$E_{\text {triplet }}=-2789.46937207$ Hartree

$\begin{array}{llll}6 & 6.030743000 & -4.486860000 & 2.527443000 \\ 6 & 7.533194000 & -2.463561000 & 2.615007000 \\ 6 & 6.481244000 & -1.473371000 & 2.787093000 \\ 6 & 4.979291000 & -3.489437000 & 2.646278000 \\ 6 & 7.347417000 & -3.852883000 & 2.530499000 \\ 6 & 5.159612000 & -2.105923000 & 2.789603000 \\ 8 & 6.701894000 & -0.274205000 & 2.996362000 \\ & & & \mathrm{~S} 39\end{array}$




\begin{tabular}{|c|c|c|c|}
\hline 8 & 5.811249000 & -5.707057000 & 2.525442000 \\
\hline 7 & 8.524800000 & -4.558585000 & 2.554396000 \\
\hline 7 & 3.994559000 & -1.423441000 & 3.014670000 \\
\hline 7 & 2.940498000 & -2.131374000 & 3.051674000 \\
\hline 7 & 9.579224000 & -3.863567000 & 2.654957000 \\
\hline 16 & 3.310259000 & -3.830602000 & 2.786713000 \\
\hline 16 & 9.213032000 & -2.142426000 & 2.736897000 \\
\hline 6 & 7.340496000 & -1.595781000 & -0.423079000 \\
\hline 6 & 5.383745000 & -3.187191000 & -0.486210000 \\
\hline 6 & 6.155275000 & -4.404318000 & -0.628729000 \\
\hline 6 & 8.113060000 & -2.818928000 & -0.568070000 \\
\hline 6 & 5.908470000 & -1.884544000 & -0.403643000 \\
\hline 6 & 7.596638000 & -4.113669000 & -0.669781000 \\
\hline 8 & 5.655017000 & -5.526596000 & -0.782143000 \\
\hline 8 & 7.858173000 & -0.468697000 & -0.417711000 \\
\hline 7 & 4.947378000 & -0.906173000 & -0.437411000 \\
\hline 7 & 8.554063000 & -5.067036000 & -0.897112000 \\
\hline 7 & 9.747409000 & -4.635027000 & -0.971243000 \\
\hline 7 & 3.752598000 & -1.310809000 & -0.535881000 \\
\hline 16 & 9.812137000 & -2.898345000 & -0.753479000 \\
\hline 16 & 3.674206000 & -3.075314000 & -0.608500000 \\
\hline \multicolumn{4}{|c|}{$\mathbf{N N S}_{2}{ }^{2-}$ thiazyl-stacking } \\
\hline \multicolumn{4}{|c|}{$E_{\text {singlet }}=-2789.44120527$ Hartree } \\
\hline \multicolumn{4}{|c|}{$\mathrm{E}_{\text {triplet }}=-2789.44880107$ Hartree } \\
\hline 6 & 6.013811000 & -4.508354000 & 2.258325000 \\
\hline 6 & 7.756561000 & -2.683686000 & 2.402462000 \\
\hline 6 & 6.833034000 & -1.577114000 & 2.507549000 \\
\hline 6 & 5.092805000 & -3.384150000 & 2.234736000 \\
\hline 6 & 7.399046000 & -4.043226000 & 2.305494000 \\
\hline 6 & 5.442571000 & -2.036388000 & 2.370218000 \\
\hline 8 & 7.164970000 & -0.400780000 & 2.711277000 \\
\hline 8 & 5.635380000 & -5.690770000 & 2.283096000 \\
\hline 7 & 8.469776000 & -4.885420000 & 2.246946000 \\
\hline 7 & 4.364557000 & -1.191346000 & 2.384390000 \\
\hline 7 & 3.227944000 & -1.744889000 & 2.269788000 \\
\hline 7 & 9.611730000 & -4.321727000 & 2.257601000 \\
\hline 16 & 3.384964000 & -3.494449000 & 2.134096000 \\
\hline 16 & 9.467420000 & -2.578418000 & 2.365601000 \\
\hline 6 & 10.303907000 & -1.935247000 & -0.789277000 \\
\hline 6 & 8.561868000 & -3.760447000 & -0.934009000 \\
\hline 6 & 9.485911000 & -4.866808000 & -1.038868000 \\
\hline 6 & 11.225249000 & -3.059051000 & -0.765580000 \\
\hline 6 & 8.918926000 & -2.400877000 & -0.837260000 \\
\hline 6 & 10.876087000 & -4.407026000 & -0.901189000 \\
\hline 8 & 9.154273000 & -6.043115000 & -1.242983000 \\
\hline 8 & 10.681914000 & -0.752609000 & -0.813883000 \\
\hline 7 & 7.847727000 & -1.558995000 & -0.779742000 \\
\hline 7 & 11.954452000 & -5.251560000 & -0.915400000 \\
\hline 7 & 13.090819000 & -4.697560000 & $\begin{array}{l}-0.800641000 \\
\text { S40 }\end{array}$ \\
\hline
\end{tabular}




$\begin{array}{lrrr}7 & 6.706102000 & -2.122891000 & -0.791698000 \\ 16 & 12.933041000 & -2.948033000 & -0.664794000 \\ 16 & 6.851152000 & -3.866593000 & -0.898901000\end{array}$

$\mathbf{N S N}_{2} 10 \AA$

$\mathrm{E}_{\text {singlet }}=-2789.37492925$

$6-1.695832000$

$6 \quad 3.847707000$

$6 \quad 3.921344000$

$\begin{array}{ll}6 & 1.769787000\end{array}$

$6 \quad 2.816416000$

$6 \quad 2.801004000$

$8 \quad 4.787493000$

$8 \quad 0.829049000$

$7 \quad 4.738163000$

$7 \quad 2.944297000$

$7 \quad 0.879695000$

$7 \quad 2.673283000$

$16 \quad 1.329954000$

$16 \quad 4.288387000$

$6 \quad-7.571196000$

$6 \quad-5.430480000$

$6 \quad-5.338607000$

$6 \quad-7.479738000$

$6 \quad-6.464941000$

$6-6.445134000$

$8 \quad-4.469015000$

$8 \quad-8.440088000$

$7 \quad-4.555040000$

$7 \quad-6.354265000$

$7 \quad-8.355886000$

$7-6.556287000$

$16 \quad-7.889301000$

$16 \quad-5.021813000$
$-6.115684000$

$-5.350951000$

$-4.028950000$

$-4.793917000$

$-6.318002000$

$-3.826832000$

$-3.216243000$

$-6.927844000$

$-5.734938000$

$-7.417164000$

$-4.410175000$

$-2.727963000$

$-2.918388000$

$-7.227201000$

1.947922000

2.696975000

4.019030000

3.270281000

1.737109000

4.230059000

4.825068000

1.141283000

2.306311000

0.636666000

3.661456000

5.331032000

5.151076000

0.816954000
$-4.068397000$

$-5.273820000$

$-4.580718000$

$-3.374701000$

$-5.036284000$

$-3.612214000$

$-4.780158000$

$-3.869236000$

$-6.169985000$

$-5.756600000$

$-2.478062000$

$-2.891411000$

$-1.974263000$

$-6.672565000$

7.424968000

6.189885000

6.880877000

8.115255000

6.442210000

7.862985000

6.669469000

7.636727000

5.281896000

5.720978000

9.022337000

8.583320000

9.517313000

4.786083000

$\mathbf{N S N}_{2} \pi$-stacking

$E_{\text {singlet }}=-2789.39606378$

$6 \quad-5.014178000$

$6 \quad-5.200972000$

6.413747000

$-8.991386000$

6.031108000

$-10.352966000$

$6 \quad-5.908620000$

6.772393000

$-11.341603000$

$6-6.543091000$

8.088872000

$-10.994857000$

$6-6.351856000$

8.499868000

$-9.564101000$

$6 \quad-5.630918000$

7.661987000

$-8.667608000$

$7 \quad-5.991105000$

6.324906000

$-12.564785000$

$7-6.837186000$

9.639435000

$-9.150798000$

$16-6.573375000$

10.008661000

$-7.586049000$

$16-5.464471000$

8.264293000

$-7.057664000$

$16-5.238456000$

4.908879000

$-12.866844000$

16

$-4.482493000$

4.552771000

$-10.896470000$ 


$\begin{array}{lrrr}8 & -4.355644000 & 5.737321000 & -8.168287000 \\ 8 & -7.137413000 & 8.762734000 & -11.798184000 \\ 16 & -2.009381000 & 8.298623000 & -7.889925000 \\ 6 & -3.479574000 & 8.892914000 & -12.165406000 \\ 6 & -3.745794000 & 9.840249000 & -11.135692000 \\ 6 & -2.697863000 & 7.645877000 & -11.865154000 \\ 6 & -3.325183000 & 9.742006000 & -9.775878000 \\ 6 & -2.250213000 & 7.534763000 & -10.436541000 \\ 6 & -2.568114000 & 8.560544000 & -9.503235000 \\ 7 & -1.579170000 & 6.482624000 & -10.051994000 \\ 16 & -1.140455000 & 6.442430000 & -8.483384000 \\ 7 & -3.936155000 & 9.087894000 & -13.371932000 \\ 16 & -4.813653000 & 10.445745000 & -13.599705000 \\ 16 & -4.696086000 & 11.209060000 & -11.603039000 \\ 8 & -2.466564000 & 6.800765000 & -12.692645000 \\ 8 & -3.609752000 & 10.593287000 & -8.902547000\end{array}$

$\mathbf{N S N}_{2}$ thiazyl-stacking

$\begin{array}{lrrr}\mathrm{E}_{\text {singlet }}=-2789.39633763 & & \\ 6 & -0.373953000 & -3.687723000 & -2.435267000 \\ 6 & 0.403216000 & -2.805756000 & -0.138051000 \\ 6 & -0.223458000 & -1.465444000 & -0.297747000 \\ 6 & -1.018805000 & -2.347086000 & -2.585211000 \\ 6 & 0.320980000 & -3.843795000 & -1.122450000 \\ 6 & -0.938190000 & -1.315039000 & -1.596425000 \\ 8 & -0.208363000 & -0.609750000 & 0.555301000 \\ 8 & -0.429207000 & -4.551989000 & -3.272951000 \\ 7 & 1.041096000 & -3.163686000 & 0.960943000 \\ 7 & 0.896880000 & -4.971132000 & -0.749287000 \\ 7 & -1.753022000 & -2.015916000 & -3.632391000 \\ 7 & -1.610234000 & -0.221776000 & -1.912279000 \\ 16 & -2.307605000 & -0.499688000 & -3.363765000 \\ 16 & 1.494938000 & -4.720292000 & 0.755329000 \\ 6 & -2.345207000 & -2.569302000 & 2.079560000 \\ 6 & -3.707629000 & -2.027233000 & -0.047903000 \\ 6 & -3.947678000 & -0.595623000 & 0.317073000 \\ 6 & -2.567082000 & -1.137692000 & 2.429687000 \\ 6 & -2.952377000 & -2.936807000 & 0.761770000 \\ 6 & -3.299754000 & -0.219726000 & 1.605926000 \\ 8 & -4.589545000 & 0.160042000 & -0.366884000 \\ 8 & -1.737026000 & -3.351062000 & 2.765124000 \\ 7 & -4.148599000 & -2.559585000 & -1.172641000 \\ 7 & -2.829189000 & -4.140443000 & 0.231559000 \\ 7 & -2.074179000 & -0.590685000 & 3.524188000 \\ 7 & -3.345367000 & 1.006433000 & 2.091736000 \\ 16 & -2.505353000 & 0.987255000 & 3.496449000 \\ 16 & -3.630073000 & -4.115215000 & -1.199030000\end{array}$




\begin{tabular}{lrrr}
$\mathbf{N S N}_{2}{ }^{2-}$ & \multicolumn{4}{l}{ 10 } \\
$\mathrm{E}_{\text {singlet }}=-2789.51250020$ & Hartree & \\
$\mathrm{E}_{\text {triplet }}=-2789.51250016$ Hartree & \\
6 & 3.185150000 & -2.896741000 & -6.372563000 \\
6 & 2.537683000 & -4.853232000 & -7.900683000 \\
6 & 1.159414000 & -4.954939000 & -7.365249000 \\
6 & 1.805115000 & -2.996572000 & -5.836458000 \\
6 & 3.490291000 & -3.884962000 & -7.434196000 \\
6 & 0.852044000 & -3.965324000 & -6.303303000 \\
8 & 0.349313000 & -5.778889000 & -7.762538000 \\
8 & 3.996322000 & -2.074363000 & -5.974439000 \\
7 & 2.987513000 & -5.655131000 & -8.853359000 \\
7 & 4.671980000 & -3.942725000 & -8.028440000 \\
7 & 1.352535000 & -2.197234000 & -4.886398000 \\
7 & -0.326650000 & -3.904021000 & -5.708735000 \\
16 & -0.231141000 & -2.657767000 & -4.593533000 \\
16 & 4.574139000 & -5.191280000 & -9.146581000 \\
6 & -9.743846000 & 1.115830000 & 4.493256000 \\
6 & -8.536499000 & 2.598156000 & 2.780286000 \\
6 & -9.254503000 & 3.831924000 & 3.186097000 \\
6 & -10.460331000 & 2.348341000 & 4.897384000 \\
6 & -8.766721000 & 1.320296000 & 3.395689000 \\
6 & -10.230642000 & 3.625814000 & 4.282715000 \\
8 & -9.058815000 & 4.918660000 & 2.663878000 \\
8 & -9.939892000 & 0.028832000 & 5.016492000 \\
7 & -7.629885000 & 2.588090000 & 1.819214000 \\
7 & -8.034680000 & 0.336246000 & 2.902839000 \\
7 & -11.368807000 & 2.355463000 & 5.860867000 \\
7 & -10.961913000 & 4.614098000 & 4.773155000 \\
16 & -11.913634000 & 3.939064000 & 5.980292000 \\
16 & -7.084873000 & 1.008949000 & 1.697854000
\end{tabular}

$\begin{array}{lrrr}\mathbf{N S N}_{2}{ }^{2-} & \pi \text {-stacking } \\ \mathrm{E}_{\text {singlet }}=-2789.48438836 \text { Hartree } & \\ \mathrm{E}_{\text {triplet }}=-2789.46937207 & \text { Hartree } & \\ 6 & 0.371990000 & -5.474777000 & 1.048498000 \\ 6 & 2.347576000 & -4.483357000 & -0.303181000 \\ 6 & 1.770797000 & -3.148432000 & -0.454973000 \\ 6 & -0.118942000 & -4.081516000 & 1.036351000 \\ 6 & 1.682241000 & -5.591727000 & 0.375993000 \\ 6 & 0.562061000 & -2.986605000 & 0.351204000 \\ 8 & 2.315553000 & -2.218441000 & -1.095888000 \\ 8 & -0.171455000 & -6.390300000 & 1.659938000 \\ 7 & 3.555971000 & -4.815218000 & -0.767200000 \\ 7 & 2.400305000 & -6.704525000 & 0.411375000 \\ 7 & -1.183036000 & -3.699459000 & 1.727052000 \\ 7 & -0.032770000 & -1.806484000 & 0.548941000 \\ 16 & -1.331774000 & -2.082795000 & 1.509537000\end{array}$




$\begin{array}{lrrr}16 & 3.801685000 & -6.387689000 & -0.375185000 \\ 6 & 0.063587000 & -4.435868000 & -2.169828000 \\ 6 & 1.954625000 & -3.507593000 & -3.662326000 \\ 6 & 1.465682000 & -2.113572000 & -3.676375000 \\ 6 & -0.511115000 & -3.100315000 & -2.323235000 \\ 6 & 1.271876000 & -4.600714000 & -2.976024000 \\ 6 & 0.155773000 & -1.993774000 & -3.003845000 \\ 8 & 2.010556000 & -1.199756000 & -4.289079000 \\ 8 & -0.482662000 & -5.364470000 & -1.527990000 \\ 7 & 3.017952000 & -3.892063000 & -4.352832000 \\ 7 & 1.864787000 & -5.781998000 & -3.172607000 \\ 7 & -1.718876000 & -2.765983000 & -1.859256000 \\ 7 & -0.560535000 & -0.879863000 & -3.040334000 \\ 16 & -1.962244000 & -1.193642000 & -2.253107000 \\ 16 & 3.164041000 & -5.508784000 & -4.133881000\end{array}$

$\begin{array}{lccc}\mathbf{N S N}_{2}{ }^{2-} \text { thiazyl-stacking } & & \\ \mathrm{E}_{\text {singlet }}=-2789.47867422 & \text { Hartree } & \\ \mathrm{E}_{\text {triplet }}=-2789.47803676 \text { Hartree } & \\ 6 & -0.875404000 & -3.350391000 & -0.849599000 \\ 6 & 1.401266000 & -3.290975000 & -2.035943000 \\ 6 & 1.939625000 & -2.210895000 & -1.160725000 \\ 6 & -0.367385000 & -2.220909000 & -0.044358000 \\ 6 & 0.074041000 & -3.826700000 & -1.887554000 \\ 6 & 0.952651000 & -1.676120000 & -0.196597000 \\ 8 & 3.093999000 & -1.825150000 & -1.233841000 \\ 8 & -1.967408000 & -3.874520000 & -0.667354000 \\ 7 & 2.120033000 & -3.847721000 & -2.989328000 \\ 7 & -0.216392000 & -4.803720000 & -2.729443000 \\ 7 & -1.100095000 & -1.614208000 & 0.878614000 \\ 7 & 1.222235000 & -0.656608000 & 0.598874000 \\ 16 & -0.158533000 & -0.372835000 & 1.489143000 \\ 16 & 1.142808000 & -5.016756000 & -3.695946000 \\ 6 & -3.398507000 & 1.243137000 & -0.042331000 \\ 6 & -1.092144000 & 1.249868000 & -1.159928000 \\ 6 & -0.582820000 & 2.379998000 & -0.356348000 \\ 6 & -2.858617000 & 2.323250000 & 0.831860000 \\ 6 & -2.412575000 & 0.706454000 & -1.006373000 \\ 6 & -1.531078000 & 2.857825000 & 0.682072000 \\ 8 & 0.509287000 & 2.903249000 & -0.540016000 \\ 8 & -4.553290000 & 0.858611000 & 0.031705000 \\ 7 & -0.360490000 & 0.641668000 & -2.082685000 \\ 7 & -2.683526000 & -0.313541000 & -1.800832000 \\ 7 & -3.576193000 & 2.881285000 & 1.785400000 \\ 7 & -1.239102000 & 3.835094000 & 1.523047000 \\ 16 & -2.597363000 & 4.050035000 & 2.490487000 \\ 16 & -1.303556000 & -0.599316000 & -2.691693000\end{array}$




$\begin{array}{lrrr}\mathbf{N S S}_{2} 10 & \AA & & \\ \mathrm{E}_{\text {singlet }}=-4163.17162652 & \text { Hartree } & \\ 6 & 5.526806000 & 1.340981000 & -1.093615000 \\ 6 & 4.722582000 & 2.424291000 & -1.568715000 \\ 6 & 4.114822000 & 3.432417000 & -0.771910000 \\ 6 & 4.289479000 & 3.422949000 & 0.723417000 \\ 6 & 5.137114000 & 2.288852000 & 1.234891000 \\ 6 & 5.688709000 & 1.343479000 & 0.327849000 \\ 7 & 3.402116000 & 4.373254000 & -1.327718000 \\ 7 & 5.360258000 & 2.182486000 & 2.515909000 \\ 16 & 6.292379000 & 0.919197000 & 2.980531000 \\ 16 & 6.642752000 & 0.087429000 & 1.037672000 \\ 16 & 3.267518000 & 4.303970000 & -2.958419000 \\ 16 & 4.447952000 & 2.543855000 & -3.272558000 \\ 8 & 6.035836000 & 0.482688000 & -1.842005000 \\ 8 & 3.795724000 & 4.248005000 & 1.445204000 \\ 16 & -2.691973000 & 9.756009000 & -10.612531000 \\ 6 & -3.367395000 & 10.027805000 & -15.121077000 \\ 6 & -3.923587000 & 10.968518000 & -14.211997000 \\ 6 & -2.519245000 & 8.893249000 & -14.611474000 \\ 6 & -3.766153000 & 10.965634000 & -12.790035000 \\ 6 & -2.349229000 & 8.878151000 & -13.115656000 \\ 6 & -2.961408000 & 9.881923000 & -12.316742000 \\ 7 & -1.636480000 & 7.936448000 & -12.561371000 \\ 16 & -1.507178000 & 7.999427000 & -10.929986000 \\ 7 & -3.586746000 & 10.138872000 & -16.402353000 \\ 16 & -4.519783000 & 11.402265000 & -16.864840000 \\ 16 & -4.877762000 & 12.225617000 & -14.919788000 \\ 8 & -2.021724000 & 8.071975000 & -15.334985000 \\ 8 & -4.279112000 & 11.819997000 & -12.039835000\end{array}$

$\mathbf{N S S}_{2} \pi$-stacking

$E_{\text {singlet }}=-4163.20542837$ Hartree

$\begin{array}{lrrr}6 & 3.960264000 & 10.300112000 & -2.369534000 \\ 6 & 2.707919000 & 10.655057000 & -2.969074000 \\ 6 & 1.480526000 & 9.945713000 & -2.835554000 \\ 6 & 1.414858000 & 8.677368000 & -2.033099000 \\ 6 & 2.710216000 & 8.322054000 & -1.360043000 \\ 6 & 3.874661000 & 9.114584000 & -1.569119000 \\ 7 & 0.393998000 & 10.411191000 & -3.393202000 \\ 7 & 2.757474000 & 7.292574000 & -0.556277000 \\ 16 & 4.198832000 & 7.001631000 & 0.156128000 \\ 16 & 5.293511000 & 8.609553000 & -0.725107000 \\ 16 & 0.552849000 & 11.811825000 & -4.219576000 \\ 16 & 2.644999000 & 12.104044000 & -3.905329000 \\ 8 & 5.000555000 & 10.970120000 & -2.498886000 \\ 8 & 0.410070000 & 8.025870000 & -1.913423000 \\ 16 & 0.758125000 & 8.504014000 & -6.264604000\end{array}$




$\begin{array}{lrrr}6 & 4.578415000 & 7.177129000 & -4.161838000 \\ 6 & 3.352878000 & 6.464912000 & -4.025735000 \\ 6 & 4.639709000 & 8.445167000 & -4.965292000 \\ 6 & 2.098737000 & 6.816684000 & -4.623099000 \\ 6 & 3.342236000 & 8.797290000 & -5.635884000 \\ 6 & 2.180076000 & 8.002319000 & -5.423955000 \\ 7 & 3.290930000 & 9.826433000 & -6.439940000 \\ 16 & 1.847292000 & 10.113802000 & -7.149243000 \\ 7 & 5.666931000 & 6.714571000 & -3.605767000 \\ 16 & 5.512815000 & 5.314287000 & -2.777938000 \\ 16 & 3.420953000 & 5.016595000 & -3.088755000 \\ 8 & 5.642792000 & 9.098831000 & -5.087360000 \\ 8 & 1.060134000 & 6.144459000 & -4.491704000\end{array}$

$\mathbf{N S S}_{2}$ thiazyl-stacking

$\mathrm{E}_{\text {singlet }}=-4163.19126352$ Hartree

$\begin{array}{lrrr}6 & 2.231960000 & 3.958193000 & -4.444349000 \\ 6 & 0.915994000 & 4.352390000 & -4.845245000 \\ 6 & -0.031477000 & 5.039584000 & -4.039741000 \\ 6 & 0.305742000 & 5.414849000 & -2.621900000 \\ 6 & 1.698514000 & 5.035928000 & -2.201134000 \\ 6 & 2.552289000 & 4.347579000 & -3.104261000 \\ 7 & -1.196885000 & 5.369427000 & -4.526437000 \\ 7 & 2.118336000 & 5.355931000 & -1.007722000 \\ 16 & 3.655661000 & 4.916167000 & -0.646290000 \\ 16 & 4.133219000 & 3.976987000 & -2.511135000 \\ 16 & -1.468005000 & 4.929350000 & -6.085041000 \\ 16 & 0.418785000 & 3.994577000 & -6.460452000 \\ 8 & 3.026004000 & 3.352382000 & -5.188661000 \\ 8 & -0.470397000 & 5.974310000 & -1.892474000 \\ 16 & -0.022926000 & 8.959257000 & -3.574736000 \\ 6 & -1.297603000 & 7.917692000 & -7.835495000 \\ 6 & -2.152610000 & 8.605730000 & -6.933288000 \\ 6 & 0.094797000 & 7.539142000 & -7.413175000 \\ 6 & -1.833888000 & 8.995028000 & -5.592794000 \\ 6 & 0.430512000 & 7.914807000 & -5.995083000 \\ 6 & -0.518187000 & 8.601397000 & -5.190545000 \\ 7 & 1.595673000 & 7.585748000 & -5.507265000 \\ 16 & 1.864808000 & 8.025773000 & -3.948274000 \\ 7 & -1.716006000 & 7.597552000 & -9.029362000 \\ 16 & -3.253100000 & 8.036745000 & -9.392461000 \\ 16 & -3.733011000 & 8.975775000 & -7.528142000 \\ 8 & 0.871719000 & 6.979496000 & -8.141626000 \\ 8 & -2.628981000 & 9.600421000 & -4.849239000\end{array}$

$\mathbf{N S S}_{2}{ }^{2-} 10 \AA$

$E_{\text {singlet }}=-4163.30890996$ Hartree

$E_{\text {triplet }}=-4163.33665083$ Hartree

$\begin{array}{llcc}6 & 5.597203000 & -1.390229000 & -7.593060000 \\ \text { S46 }\end{array}$ 


$\begin{array}{lrrr}6 & 4.789510000 & -0.236898000 & -7.329695000 \\ 6 & 4.566262000 & 0.335386000 & -6.065463000 \\ 6 & 5.211189000 & -0.281678000 & -4.848238000 \\ 6 & 6.064927000 & -1.498545000 & -5.115538000 \\ 6 & 6.202523000 & -1.965938000 & -6.433599000 \\ 7 & 3.810355000 & 1.398209000 & -5.896471000 \\ 7 & 6.652224000 & -2.078660000 & -4.092154000 \\ 16 & 7.572425000 & -3.416051000 & -4.502324000 \\ 16 & 7.222962000 & -3.397355000 & -6.645445000 \\ 16 & 3.146485000 & 2.000329000 & -7.304611000 \\ 16 & 3.990846000 & 0.559045000 & -8.688045000 \\ 8 & 5.759809000 & -1.857127000 & -8.749512000 \\ 8 & 5.055493000 & 0.166652000 & -3.736233000 \\ 16 & -3.645585000 & 10.831469000 & -9.087654000 \\ 6 & -5.756222000 & 12.860728000 & -12.654944000 \\ 6 & -5.875893000 & 13.341827000 & -11.340069000 \\ 6 & -4.910167000 & 11.638115000 & -12.920449000 \\ 6 & -5.258371000 & 12.775557000 & -10.182396000 \\ 6 & -4.252482000 & 11.030920000 & -11.705088000 \\ 6 & -4.458104000 & 11.616669000 & -10.444036000 \\ 7 & -3.502445000 & 9.963720000 & -11.872647000 \\ 16 & -2.823403000 & 9.373331000 & -10.466774000 \\ 7 & -6.354029000 & 13.432700000 & -13.676826000 \\ 16 & -7.264354000 & 14.777507000 & -13.268874000 \\ 16 & -6.888545000 & 14.779044000 & -11.130134000 \\ 8 & -4.769777000 & 11.178092000 & -14.029713000 \\ 8 & -5.405012000 & 13.254650000 & -9.028801000\end{array}$

\begin{tabular}{|c|c|c|c|}
\hline \multicolumn{4}{|c|}{$\mathbf{N S S}_{2}^{2-} \pi$-stacking } \\
\hline \multicolumn{4}{|c|}{$E_{\text {singlet }}=-4163.30359395$ Hartree } \\
\hline \multicolumn{4}{|c|}{$E_{\text {triplet }}=-4163.29726872$ Hartree } \\
\hline 6 & -5.190128000 & 6.515941000 & -9.490630000 \\
\hline 6 & -5.744730000 & 7.115159000 & -10.666346000 \\
\hline 6 & -6.785895000 & 8.068082000 & -10.679644000 \\
\hline 6 & -7.327690000 & 8.598593000 & -9.379878000 \\
\hline 6 & -6.674160000 & 8.047465000 & -8.134401000 \\
\hline 6 & -5.680676000 & 7.056652000 & -8.265136000 \\
\hline 7 & -7.353357000 & 8.459967000 & -11.796955000 \\
\hline 7 & -7.075734000 & 8.506623000 & -6.973163000 \\
\hline 16 & -6.257584000 & 7.830160000 & -5.664128000 \\
\hline 16 & -5.027880000 & 6.407600000 & -6.751460000 \\
\hline 16 & -6.681414000 & 7.827797000 & -13.171985000 \\
\hline 16 & -5.235648000 & 6.523198000 & -12.241134000 \\
\hline 8 & -4.328895000 & 5.598772000 & -9.537697000 \\
\hline 8 & -8.247791000 & 9.384344000 & -9.331727000 \\
\hline 16 & -3.553224000 & 9.423555000 & -8.579019000 \\
\hline 6 & -2.115323000 & 7.897915000 & -12.685408000 \\
\hline 6 & -3.108137000 & 8.889461000 & -12.554887000 \\
\hline 6 & -1.461534000 & 7.347285000 & $\begin{array}{c}-11.439836000 \\
\text { S47 }\end{array}$ \\
\hline
\end{tabular}




$\begin{array}{lrrr}6 & -3.598171000 & 9.430904000 & -11.329513000 \\ 6 & -2.003512000 & 7.877809000 & -10.140173000 \\ 6 & -3.044251000 & 8.831241000 & -10.153647000 \\ 7 & -1.436230000 & 7.485902000 & -9.022786000 \\ 16 & -2.108006000 & 8.118414000 & -7.647866000 \\ 7 & -1.714501000 & 7.437821000 & -13.846506000 \\ 16 & -2.532929000 & 8.113815000 & -15.155624000 \\ 16 & -3.760768000 & 9.538379000 & -14.068627000 \\ 8 & -0.541042000 & 6.561988000 & -11.487850000 \\ 8 & -4.458521000 & 10.348915000 & -11.282657000\end{array}$

$\begin{array}{lrrr}\mathbf{N S S}_{2}{ }^{2-} \text { thiazyl-stacking } & & \\ \mathrm{E}_{\text {singlet }}=-4163.30947018 & \text { Hartree } & \\ \mathrm{E}_{\text {triplet }}=-4163.29885209 & \text { Hartree } & \\ 6 & 4.480164000 & 9.708138000 & -0.716857000 \\ 6 & 3.447021000 & 9.636531000 & -1.750430000 \\ 6 & 2.211041000 & 8.995106000 & -1.621944000 \\ 6 & 1.922249000 & 8.207979000 & -0.381190000 \\ 6 & 2.996842000 & 8.260123000 & 0.686945000 \\ 6 & 4.175314000 & 9.002729000 & 0.460188000 \\ 7 & 1.294850000 & 9.045032000 & -2.581481000 \\ 7 & 2.771161000 & 7.602513000 & 1.796094000 \\ 16 & 4.008147000 & 7.723222000 & 2.932833000 \\ 16 & 5.370965000 & 8.988272000 & 1.795766000 \\ 16 & 1.747332000 & 9.929283000 & -3.902185000 \\ 16 & 3.698619000 & 10.544030000 & -3.217107000 \\ 8 & 5.536909000 & 10.364301000 & -0.905892000 \\ 8 & 0.897963000 & 7.576202000 & -0.238990000 \\ 16 & 0.731262000 & 8.019497000 & -8.987722000 \\ 6 & 3.890726000 & 8.012950000 & -5.569677000 \\ 6 & 2.654664000 & 7.371574000 & -5.441238000 \\ 6 & 4.179684000 & 8.800040000 & -6.810426000 \\ 6 & 1.621611000 & 7.300102000 & -6.474850000 \\ 6 & 3.105178000 & 8.747933000 & -7.878647000 \\ 6 & 1.926694000 & 8.005365000 & -7.651949000 \\ 7 & 3.330936000 & 9.405583000 & -8.987770000 \\ 16 & 2.093827000 & 9.285128000 & -10.124456000 \\ 7 & 4.806829000 & 7.962992000 & -4.610099000 \\ 16 & 4.354310000 & 7.078721000 & -3.289430000 \\ 16 & 2.403071000 & 6.463995000 & -3.974587000 \\ 8 & 5.203999000 & 9.431798000 & -6.952479000 \\ 8 & 0.564760000 & 6.644099000 & -6.285869000\end{array}$




\section{References}

(1) Groß, W.; Oberkobusch, D.; Benicke, W. Mittel Zum Farben von Keratinhaltigen Fasern. German Patent DE 102008062236 A1, 2009.

(2) Balli, H.; Kersting, F. AZIDINIUMSALZE, I Synthese Quasiaromatischer AzidocyclimoniumFluoroborate. Justus Liebigs Ann. Chem. 1961, 647, 1-10. DOI:10.1002/jlac.19616470102.

(3) Maier, G.; Schrot, J.; Reisenauer, H. P. Heterocumulene, 6 C5OS (5-Thioxo-1,2,3,4-Pentatetraen-1-on)

- Darstellung Und Spektroskopische Eigenschaften. Chem. Ber. 1991, 124, 2613-2616. DOI:10.1002/cber.19911241135.

(4) Wang, Y. Anodic Modification Thin-Film Material and Application Thereof in Electroluminescent Device. Chinese Patent CN103896966A, 2014.

(5) Shi, S.; Katz, T. J.; Yang, B. V.; Liu, L. Use of Thiazyl Chloride, Alkyl Carbamates, and Thionyl Chloride to Fuse 1,2,5-Thiadiazoles to Quinones and to Oxidize, Chlorinate, and Aminate Them. J. Org. Chem. 1995, 60, 1285-1297. DOI:10.1002/chin.199535124.

(6) Prior, A.; Sun, D. Scope and Optimization of the Double Knorr Cyclization: Synthesis of Novel Symmetrical and Unsymmetrical Tricyclic 1,8-Diazaanthraquinones. Synthesis (Stuttg). 2018, 50, 859871. DOI:10.1055/s-0036-1589134.

(7) Mailman, A.; Leitch, A. A.; Yong, W.; Steven, E.; Winter, S. M.; Claridge, R. C. M.; Assoud, A.; Tse, J. S.; Desgreniers, S.; Secco, R. A.; et al. The Power of Packing: Metallization of an Organic Semiconductor Chart 1 Scheme 1. J. Am. Chem. Soc 2017, 139, 25. DOI:10.1021/jacs.6b12814.

(8) Lekin, K.; Leitch, A. A.; Assoud, A.; Yong, W.; Desmarais, J.; Tse, J. S.; Desgreniers, S.; Secco, R. A.; Oakley, R. T. Benzoquinone-Bridged Heterocyclic Zwitterions as Building Blocks for Molecular Semiconductors and Metals. Inorg. Chem. 2018, 57, 4757-4770. DOI:10.1021/acs.inorgchem.8b00485.

(9) Frisch, M. J.; Trucks, G. W.; Schlegel, H. B.; Scuseria, G. E.; Robb, M. A.; Cheeseman, J. R.; Scalmani, G.; Barone, V.; Mennucci, B.; Petersson, G. A.; Nakatsuji, H.; Caricato, M.; Li, X.; Hratchian, P. H.; Izmaylov, A. F.; Bloino, J.; Zheng, G.; Sonnenberg, J. L.; Had, M.; Fox, D. J. Gaussian 09, Revision D.01, Gaussian, Inc., Wallingford CT,. 2009.

(10) Becke, A. D. Density-functional Thermochemistry. III. The Role of Exact Exchange. J. Chem. Phys. 1993, 98, 5648-5652. DOI:10.1063/1.464913.

(11) Miehlich, B.; Savin, A.; Stoll, H.; Preuss, H. Results Obtained with the Correlation Energy Density Functionals of Becke and Lee, Yang and Parr. Chem. Phys. Lett. 1989, 157, 200-206. DOI:10.1016/0009-2614(89)87234-3.

(12) McLean, A. D.; Chandler, G. S. Contracted Gaussian Basis Sets for Molecular Calculations. I. Second 
Row Atoms, $\mathrm{Z}=11-18$. J. Chem. Phys. 1980, 72, 5639-5648. DOI:10.1063/1.438980.

(13) Krishnan, R.; Binkley, J. S.; Seeger, R.; Pople, J. A. Self-Consistent Molecular Orbital Methods. XX. A Basis Set for Correlated Wave Functions. J. Chem. Phys. 1980, 72, 650-654. DOI:10.1063/1.438955.

(14) Grimme, S.; Antony, J.; Ehrlich, S.; Krieg, H. A Consistent and Accurate Ab Initio Parametrization of Density Functional Dispersion Correction (DFT-D) for the 94 Elements H-Pu. J. Chem. Phys. 2010, 132, 154104. DOI:10.1063/1.3382344.

(15) Cui, Z. H.; Lischka, H.; Beneberu, H. Z.; Kertesz, M. Double Pancake Bonds: Pushing the Limits of Strong $\pi-\pi$ Stacking Interactions. J. Am. Chem. Soc. 2014, 136, 12958-12965. DOI:10.1021/ja505624y. 